\title{
Tackling thermal integration in the synthesis of polygeneration systems for buildings
}

\author{
Eduardo A. Pina ${ }^{1 *}$, Miguel A. Lozano ${ }^{1}$, José C. $\operatorname{Ramos}^{2}$, Luis M. Serra ${ }^{1}$ \\ ${ }^{1}$ GITSE-I3A, Dept. of Mechanical Engineering, University of Zaragoza, Spain \\ ${ }^{2}$ Dept. of Energy and Mechanical Engineering, University of Engineering and Technology, \\ Peru. \\ *corresponding author; email: epina@unizar.es.
}

\begin{abstract}
A novel methodology is proposed for the synthesis of polygeneration systems in tertiary sector buildings with detailed thermal integration. The methodology involves a systematic approach that combines Pinch Analysis, mathematical programming, and the definition of a superstructure with thermal flexibility whereby mass flows can exchange heat in various temperature intervals. With the detailed characterization of the thermal energy flows associated with the thermal energy technologies and services to be supplied to the building, the optimization procedure provides a more realistic system configuration, ensures that thermodynamic principles are satisfied, and allows for synergies and potential benefits to emerge. The methodology is first introduced through a simple example of a gas engine-based energy system, highlighting the necessity of a detailed characterization of the hot and cold flows regarding their quantity and quality levels. Then, the approach is applied to the case study of a Brazilian university hospital that requires electricity, steam, hot water, and chilled water. The optimization is formulated as a multi-period mixed integer linear programming model that minimizes the total annual cost of installing and operating the system using local-based data. The results show the technical and economic interest of deploying cogeneration gas engines to cover electricity and thermal energy services. Besides, a strong synergy is observed between the cogeneration gas engine and the single-effect absorption chiller. Thus, it is demonstrated how a preliminary analysis of thermal integration opportunities must be an integral part of the optimal synthesis of energy supply systems.
\end{abstract}

Keywords: buildings, energy systems, MILP, optimization, polygeneration, thermal integration.

\section{Introduction}

\subsection{The synthesis of polygeneration systems for buildings}

Polygeneration is defined as the production of two or more energy services from a common energy resource. Typical polygeneration schemes include cogeneration, or Combined Heat and Power (CHP), and trigeneration, or Combined Cooling, Heat and Power (CCHP) [1-3], but various system configurations are possible [4,5]. For decades, the industrial sector has successfully deployed polygeneration systems to promote primary energy savings, increase energy efficiency, reduce unit costs of final products, and mitigate environmental impacts of its processes [6,7]. Nevertheless, there is still a largely untapped potential for these systems in residential and tertiary sector applications [8]. 
One of the decisive factors for this condition is the challenge of carrying out a robust and comprehensive synthesis procedure that must consider the multi-faceted nature of polygeneration systems for buildings [9,10]: multiple energy resources (renewable and nonrenewable), multiple energy products (electricity, steam, hot water, chilled water), multiple technology options (generation, transformation and storage technologies), and multiple operation periods (hourly and seasonal variations in energy resources, energy demands and climatic conditions, and temporal variations in energy prices).

The goal of the synthesis problem is to determine the optimal plant configuration (what technologies to install and with what capacities) and operational planning (operational state of the devices, energy flow rates, electricity purchase/sale, etc.) [11-13]. Traditionally, this procedure followed previous experience based on existing design solutions. A more advanced strategy consists, first, in the preliminary identification of a superstructure that includes all feasible solutions to the synthesis problem and, second, in the selection of the system configuration from this superstructure through an optimization procedure.

Clearly, the choice of the best system configuration is a complex task in which the definition of the superstructure plays a key role. In this regard, it has been demonstrated by the authors in previous studies regarding the synthesis of energy supply systems for hospital facilities in Spain [14] and in Brazil [15], that a good configuration must achieve a high level of thermal exergy recovery, enabling the use of thermal levels in the construction of the proposed superstructure and ensuring that thermodynamic principles are satisfied. Therefore, the synthesis procedure requires (i) considering a diverse range of technologies and interconnections between them to supply the energy services required with different energy resources, thus allowing for potential synergies to arise; and (ii) simultaneously taking into account the multi-period operation of the system with varying energy services demands. More particularly, a realistic combination of thermal flows and technologies in the superstructure can only be achieved by acknowledging, among others, that (iii) polygeneration systems feature multiple heat sources and internal heat demands, which are typically supplied/required at various temperatures and may consist of different material flows (e.g. hot water, steam, exhaust gas); and (iv) the consumer center's thermal energy demands are often varied and present different temperatures. It follows that $(\mathrm{v})$ the superstructure must allow for thermodynamically consistent matches between the heat flows supplied by generation technologies and the heat flows required by transformation technologies and/or the end user. Consequently, the synthesis must be approached from both supply and demand sides.

At the supply side, the complex interactions (e.g. synergies and competitions) between technologies must be considered. Synergy benefits can be achieved by energy cascading, in which the by-product of a technology is used as fuel for another [16,17], for instance the use of cogenerated heat to drive a thermally activated technology (TAT), such as an absorption chiller, for cooling production. Besides, the way in which two or more technologies are connected and set to operate can increase potential benefits, for example by coupling solar thermal collectors, borehole thermal energy storage and auxiliary heating (e.g. heat pump). At the consumer level, the technologies installed to deliver the thermal energy and the corresponding temperature levels of the required thermal energy flows will influence the selection of technologies and their 
operation [18]. Additionally, the hourly and seasonal fluctuations of energy services demands must not be overlooked, since they may increase the interest for alternative productive trajectories, for instance a gas engine that in the winter provides heat for space heating, and in the summer provides heat for cooling production in an absorption chiller [14].

The issue is that studies reported in the literature on the optimal synthesis and design of energy supply systems for residential and commercial applications have generally disregarded the different thermal levels of the heat supply and demand that exist in those systems. As will be discussed in the following section, in a problem that proposes to evaluate different alternatives, such as the synthesis problem, it is crucial to explicitly model the thermal flows in terms of both their quantity $(\mathrm{kWh})$ and quality (temperature) levels.

\subsection{The issue of thermal integration in energy systems for buildings}

Process Integration techniques are required for an appropriate match between heat sources and sinks associated with the plant equipment and the building's thermal demands. Heat integration based on the Pinch Analysis method, developed by Linnhoff et al. [19] in 1982, has been one of the most important contributions to the field of Process Integration. Since then, a long and fruitful path has been trodden as shown, for example, in references [20-22]. In 2007, Kemp [20] published an update to Linnhoff's seminal book [19]. The book edited by Klemeš [21] in 2013 highlighted the progress made so far, showing that process integration has matured as a discipline by extending the initial heat integration into more general energy integration of processes and systems. More recently, in 2017, El-Halwagi [22] made evident the application of the concepts and techniques of process integration to maximize the efficiency and sustainability of industrial processes.

The Pinch method seeks to represent and calculate the thermal integration potential of technologies and utilities before approaching the design stage of an energy system. This is achieved through the concept of thermal cascade as a representation that combines the first law (energy conservation) and second law (without intervening other energy resources, heat is only transferred from hotter bodies to colder ones) of thermodynamics with the method of Problem Table algorithm for the calculation of the feasible options and the determination of achievable objectives: minimum consumption of external utilities, minimum cost, etc. Pinch Analysis is a mature and realistic procedure whose limitations are also the major drivers for its combination with mathematical programming approaches, more particularly mixed integer linear (and nonlinear) formulations.

The interest of combining a thermodynamic analysis tool, such as the Pinch method, with another numerical optimization tool, such as the mixed integer linear programming (MILP) formulation, in industrial applications has been shown by several works, among which are notorious examples the transshipment models to assess minimum utility targeting by Papoulias and Grossman [23], the methodology formulated by Maréchal [24] for the process integration of industrial sites, and the systematic approach by Shang and Kokossis [25] for optimizing total site utility systems. These studies have been primarily oriented towards the design of heat exchanger networks (HENs) in which steam turbines typically functioned as power generation 
units and steam as working medium providing latent heat at the required temperature and pressure levels. In the case of residential and commercial applications, however, instead of steam turbines and steam networks, there are mainly internal combustion engines (ICEs), supplying several sensible heat sources (e.g. jacket cooling water, lubricating oil, charge air, exhaust gas), or gas turbines (GT), supplying one sensible heat source (e.g. exhaust gas).

Overall, the existing literature on the synthesis of polygeneration systems for building applications does not explicitly consider the energy quality (temperature level) of the different heat sources and demands involved. In these studies, (i) heat is treated as a homogeneous flow; (ii) it is assumed that all waste heat can be recovered at the same temperature level; (iii) a (constant or variable) thermal efficiency is used to determine the amount of recoverable heat; and (iv) the heat flows produced by the different technologies are mixed in a homogeneous flow which is then used for different applications (e.g. heating load, absorption chillers, thermal energy storage).

Some recent contributions in which heat is treated homogeneously are provided as follows. Ameri and Besharati [26] carried out the optimal design and operation of CCHP systems with GTs distributed in a residential district heating and cooling (DHC) network in Iran. Ondeck et al. [27] proposed a framework for the design and operating strategy optimization of CCHP systems with GTs operating in island mode, defining cost effective strategies to supply the energy demands of a residential neighborhood in the US. Sigarchian et al. [28] optimized the design of a polygeneration system with micro-GT for a hypothetical hospital in northern Italy from the economic, energetic and environmental viewpoints. Fuentes-Cortés et al. [29] carried out the economic and environmental multi-objective optimization (MOO) of a CHP system for residential complexes in two Mexican cities considering four different prime movers, namely ICE, stirling engine, microturbine, and fuel cell. Urbanucci and Testi [30] proposed a probabilistic approach for the optimal sizing and operation under long-term energy demand uncertainty of a CHP system with ICE for an Italian hospital. Li et al. [31] optimized a distributed CCHP system with both ICE and GT connected to a district energy network of residential and office buildings in China considering economic and environmental aspects.. Zheng et al. [32] assessed the impact of feed-in tariff policies on the design optimization and system performance of a CCHP system with ICE for a hospital in different climate zones. Wang et al. [33] presented an optimal configuration planning procedure for community level multienergy systems based on the energy hub concept and applied it to an administrative center in China.

There are, in fact, some contributions that make the distinction between two or more temperature levels of the heat production/consumption. While this approach constitutes a logical step towards a more realistic system configuration and operational planning, the thermal flexibility that it provides to the superstructure is still insufficient, since other less obvious and yet feasible combinations of thermal integration are excluded, which may prove potentially more interesting solutions. Zhu et al. [34] proposed a MOO for the synthesis, design and operation of large-scale CCHP systems in a Chinese airport; four temperature levels were considered, namely high-, medium, and low-pressure steam and hot water. Nonetheless, two temperature levels are most common. Sy et al. [35] presented a target-oriented robust 
optimization approach for the synthesis of polygeneration systems with long-term investment risk uncertainties; it was assumed that waste heat from the GT was used to produce both steam and hot water. Bahlawan et al. [36] proposed an optimal design procedure for a hybrid CCHP system minimizing primary energy consumption during the operation and throughout the life cycle of the project for a commercial and office building in Italy; solar thermal collectors were allowed to operate at two temperature levels, $50{ }^{\circ} \mathrm{C}$ in the winter and $80^{\circ} \mathrm{C}$ in the summer. $\mathrm{Wu}$ et al. [37] proposed an optimization approach to determine the optimal configuration of a CCHP system for a residential building in China and analyzed the influence of building features on the cost of the system; the waste heat from the ICE was recovered at a high-temperature that could drive an absorption heat pump and/or be downgraded to a lower-temperature to cover the heating load. Lozano et al. [12] assessed the cost optimization of the design of CCHP systems for a set of residential buildings in Spain under legal constraints regarding the self-consumption of the cogenerated heat; the waste heat from the ICE was partly recovered at a higher temperature (corresponding to the exhaust gas and jacket water) that could drive an absorption chiller, and partly recovered at a lower temperature (corresponding to the lubricating oil) to cover the heating demands. Carvalho et al. [38] proposed a multicriteria synthesis of CCHP systems for a Spanish hospital; all waste heat from the ICE was now recovered as hot water at the same temperature level, while the waste heat from the GT was used to produce both steam and hot water. Pina et al. [9] carried out a MOO procedure of CCHP systems for a residential building in Spain; it was assumed that the ICE produced high- and low-temperature heat to drive the absorption chiller and to cover the heating demands, respectively; also, solar thermal collectors operated at high-temperature in the summer and low-temperature in the winter.

A variety of studies in the literature have reported detailed thermal integration procedures that explicitly model the thermal energy flows and characterize the technologies' heat sources and heat demands. These works have approached energy supply systems from different perspectives. First, there were studies that focused on optimizing or analyzing a particular technology or thermodynamic cycle, such as different types of prime movers (e.g. ICE, microturbine, stirling engine, fuel cell) and TATs [39], and heat pumps [40,41]. Secondly, some studies analyzed the techno-economic performance of a specific system configuration, such as CHP [42], micro-CHP [43], and CCHP [44] systems. Thirdly, other studies explored the optimal design of HENs for inter-plant waste heat recovery [45]; the simultaneous design of mass allocation and heat exchange networks [46]; and total site heat integration in the context of industrial, urban and renewable energy systems [47] as well as district cooling systems [48]. Lastly, the works by Calva et al. [49] and Picón and Medina [17] proposed a fast and reliable procedure to optimize the design of thermally integrated CCHP systems based on gas turbinevapor compression chiller and steam turbine-absorption chiller using simple thermodynamic models. However, none of these contributions have approached the problem from the perspective of the synthesis of energy systems for residential and commercial buildings.

Research on the synthesis of energy systems with detailed thermal integration considerations is quite rare and has been restricted to industrial and district-scale applications. Bohlayer and Zöttl [50] proposed a MILP approach for the multi-period synthesis, design and operation of a distributed CCHP system for a manufacturing company. The system incorporates heat upgrading technologies (e.g. mechanical heat pump) for low-temperature waste heat 
exploitation. Heating and cooling flows are addressed explicitly, allowing for temperaturerelated constraints in the model. The superstructure incorporates hot and cold temperature intervals that interact with technologies and heating/cooling loads. It was demonstrated that potential economic benefits could be obtained by recycling low-temperature waste heat. Wang et al. [51] developed a MILP model for waste heat recovery in a district-scale CCHP system. The model was validated using four typical cases under different operating conditions and business models. The results allow for a more realistic configuration and operational dispatch. An energy flow cascade between 400 and $70{ }^{\circ} \mathrm{C}$ is proposed, matching the recoverable waste heat from the ICE to common thermal-driven technologies according to their suitable temperature ranges, including Rankine Cycle, Organic Rankine Cycle (ORC), single- and double-effect absorption chillers, among others. Lastly, Lythcke-Jørgensen et al. [52] presented a methodology to design flexible multi-generation systems for quick and reliable pre-feasibility analyses that simultaneously considered several aspects including the systematic heat and mass integration. The methodology was applied to the case study of a bioethanol plant.

\subsection{Objectives and contributions}

The present paper follows from a previous investigation by Ramos [18], which analyzed the synthesis of gas engine-based trigeneration systems in residential buildings. It was demonstrated that important benefits could be obtained by appropriately characterizing the gas engine according to its actual heat supply instead of the manufacturer's proposal of heat recovery scheme. Such reasoning can be extended to the synthesis problem, in which the search for good alternatives is not restricted to choosing from various technology options only, but also requires considering the multiple possibilities of thermal integration between the thermal energy flows involved, ensuring that thermodynamic principles are satisfied and allowing for potential synergies to emerge.

The literature survey conducted in the previous section indicates that overall studies on the synthesis of energy supply systems for residential and commercial buildings do not explicitly consider the energy quality (temperature) of the different thermal energy flows involved. Moreover, the few studies reported on the synthesis of energy systems with detailed thermal integration have focused exclusively on industrial and district-scale applications, which differ fundamentally from residential and commercial building applications.

Hence, this work aims to fill this research gap by proposing a novel methodology for the synthesis of polygeneration systems in tertiary sector buildings with thermal integration considerations. The methodology involves (i) the combination of Pinch Analysis, by means of the problem table algorithm, and mathematical programming, based on MILP formulation; (ii) the characterization of the thermal energy flows supplied/required by the technologies in the superstructure, as well as the thermal energy flows required by the building, in terms of their supply and target temperatures and mass flow rates; and (iii) the definition of the superstructure with thermal flexibility whereby thermal energy flows can exchange heat in various temperature intervals. Thus, the developed model provides more realistic system configurations, ensures that the second law of thermodynamics is not violated, and allows for synergies and potential benefits to emerge. 
First, a simple case study of a gas engine-based energy supply system is developed to demonstrate the application of the methodology and the necessity of a detailed characterization of thermal flows based on quality (temperature). Then, the methodology is applied to the case study of a Brazilian university hospital, assessing the technical and economic feasibility of polygeneration systems integrating gas engines, gas boilers, absorption chillers, and mechanical chillers.

\section{The Open Problem Table}

As discussed in the introduction of this paper, polygeneration systems are highly integrated energy systems whose full potential can only be achieved through an appropriate synthesis procedure that acknowledges the various heat sources and demands as regards their quantities and quality levels. In this context, the Open Problem Table (OPT) proposed herein serves as an interface between the technologies that supply heat and the technologies that require it through a virtual heat exchanger network, whereby physical and structural constraints can be imposed in synthesis and design optimization problems. Provided that the thermodynamic states of system material streams are defined (constant temperatures and pressures), heat supply and demand flows can be expressed as linear functions of mass flow rates, thus leading to simple mathematical formulations of the targeting problems, which can be easily incorporated within MILP models.

The OPT is shown in Figure 1. Based on the transshipment model for heat integration by Papoulias and Grossmann [23], the OPT can be stated as follows. In an energy supply system, there is a set of hot flows $i$ that offer heat from production technologies and a set of cold flows $j$ that are required by the consumption technologies to provide the demanded energy services. In each time period $\theta$, hot $i$ and cold $j$ flows can exchange heat in temperature intervals $k$, labeled from hottest $(k=1)$ to coldest $(k=n k)$, obtained by partitioning the entire temperature range considering the flows' initial (supply) and final (target) temperatures; a specific temperature interval is reserved for phase change at constant temperature, if applicable.

In each time period $\theta$, the heat balance in a temperature interval $k$ is expressed by Eq. (1), in which $R K(k, \theta)$ is the surplus heat of the corresponding temperature interval $k, R K(k-1, \theta)$ is the cascaded surplus heat from the previous (hotter) temperature interval $k-1, O K(k, \theta)$ is the heat supplied $\operatorname{QIK}(i, k, \theta)$ by the hot flows $i$ present in $k(\mathrm{Eq} .(2))$, and $D K(k, \theta)$ is the heat consumed $Q J K(j, k, \theta)$ by cold flows $j$ present in $k$ (Eq. (3)). The fundamental condition of the Second Law of Thermodynamics (that the surplus heat $R K(k, \theta)$ that cascades from one temperature interval to the next must be greater than or equal to zero) is satisfied by Eq. (4). 


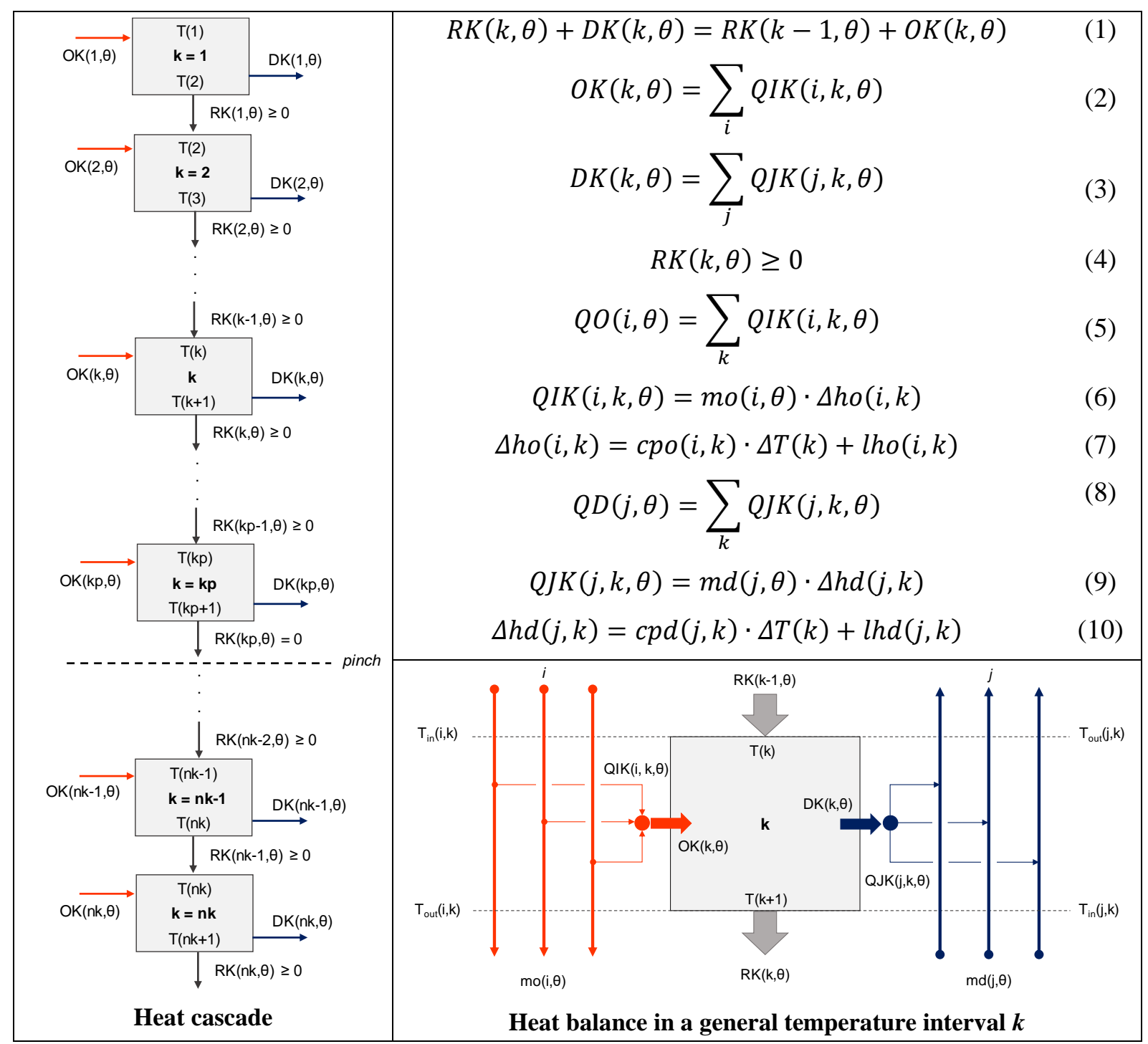

Figure 1: Open Problem Table.

The heat supplied $Q O(i, \theta)$ by a hot flow $i$ in the time period $\theta$ is the sum of the heat $Q I K(i, k, \theta)$ transferred by the flow in each temperature interval $k$ (Eq. (5)). The $Q I K(i, k, \theta)$ is, in turn, calculated as the product of the hot flow's mass rate $m o(i, \theta)$ and enthalpy change $\Delta h o(i, k)$ (Eq. (6)). The enthalpy change $\Delta h o(i, k)$ of the hot flow $i$ in the temperature interval $k$ is expressed by Eq. (7), consisting of one component relative to the sensible heat (specific heat cpo $(i, k)$ multiplied by the temperature difference of the temperature interval $\Delta T(k)$ ) and another relative to the latent heat $l h o(i, k)$. In the case of the cold flows $j$, Eqs. (8)-(10) are analogous to those presented for the hot flows $i$ (Eqs. (5)-(7)).

The surplus heat $R K(n k, \theta)$ of the last (coldest) temperature interval $n k$, if any, corresponds to the heat that must be dissipated to the environment $Q_{d i s}(\theta)$.

$Q_{\text {dis }}(\theta)=R K(n k, \theta)$

Also, there is no surplus heat into the first (hottest) temperature interval, so that $R K(0, \theta)=0$. 


\section{Simple example application: Gas engine-based energy supply system}

Gas engines are particularly suitable for residential and commercial applications owing to their high potential for heat recovery, high electrical efficiency, modular assembly, good performance at partial load operation, short time for startup and shutdown, etc. [18,29]. A drawback, however, is that these devices present dispersed heat sources, each with different temperature levels. Since a significant benefit of cogeneration lies in the recovery of useful heat, it is necessary to synthesize an adequate network of heat exchangers to recover the maximum amount of heat from the different sources supplied by the engine and take advantage of the recovered heat to attend the various thermal energy demands posed by the consumer center. In this section, the proposed method of thermal integration of processes is applied in several examples of increasing levels of complexity, finding the maximum heat that can be recovered from a gas engine, once the quantities and the thermal levels of the energy services to be supplied have been specified, which is the starting point to formulate the most appropriate heat recovery network.

Let us consider the Wärtsila 6L34DF gas engine. At nominal load, the engine presents a natural gas consumption of $F_{g e}=6225 \mathrm{~kW}$ (LHV), a net electrical power of $W_{g e}=2910 \mathrm{~kW}$, and an electric efficiency of $\eta_{w}=W_{g e} / F_{g e}=46.7 \%$. Based on the information provided by the manufacturer in the technical catalogue [53], Figure 2 shows the usable heat sources in quantity $(\mathrm{kW})$ and quality (thermal level) for the engine's operation at full load. The time period set $\theta$ will be omitted for now, since constant operation is considered.

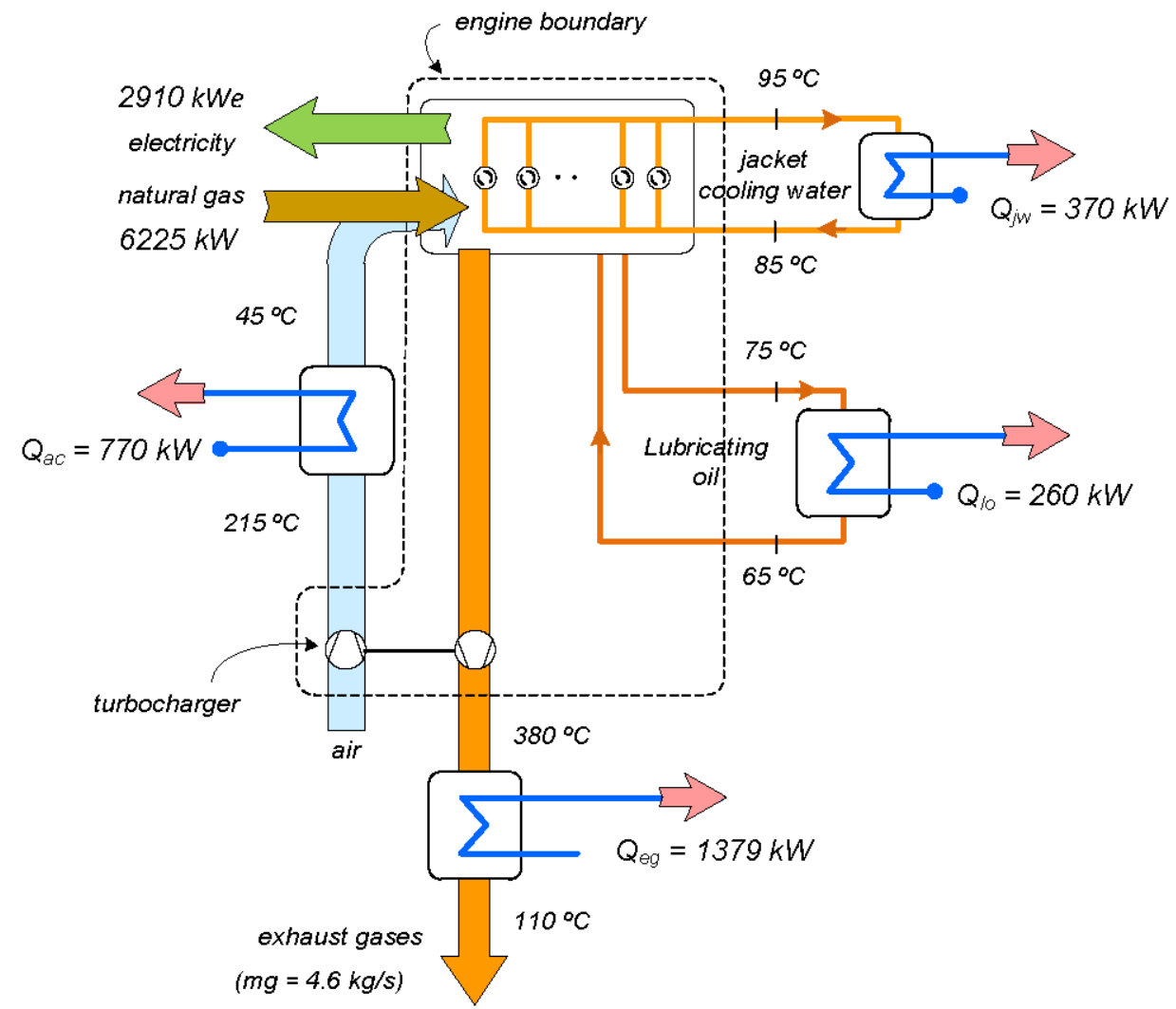

Figure 2: Usable heat sources of the gas engine Wärtsila 6L34DF at nominal load. 
As can be seen from Figure 2, the total cogenerated heat $Q_{g e}=2779 \mathrm{~kW}$ is obtained from four main heat sources, namely exhaust gas $Q_{e g}$, charge air $Q_{a c}$, jacket cooling water $Q_{j w}$, and lubricating oil $Q_{l o}$. Each heat source is associated with a hot flow, whose thermal characteristics are described in Table 1. In order to impose sufficient thermal gradient to promote the heat transfer and the production of the energy services, the shifted temperatures $T_{\text {in }}{ }^{*}$ and $T_{\text {out }}{ }^{*}$ were defined by subtracting $20^{\circ} \mathrm{C}$ for gas and air flows, and $5{ }^{\circ} \mathrm{C}$ for water and oil flows, from the corresponding supply $T_{\text {in }}$ and target $T_{\text {out }}$ temperatures.

Table 1: Heat sources supplied by the gas engine - hot flows $i$.

\begin{tabular}{|c|c|c|c|c|c|c|c|c|c|c|}
\hline Hot flow & Type & $\begin{array}{c}\mathbf{m o} \\
\mathbf{k g} / \mathbf{s}\end{array}$ & $\begin{array}{c}\boldsymbol{Q O} \\
\mathbf{k W}\end{array}$ & $\begin{array}{c}\mathbf{c p o} \\
\mathbf{k J} /(\mathbf{k g} \cdot \mathbf{K})\end{array}$ & $\begin{array}{c}\boldsymbol{l h o} \\
\mathbf{k J} / \mathbf{k g}\end{array}$ & $\begin{array}{c}\Delta T \\
\mathbf{K}\end{array}$ & $\begin{array}{c}\boldsymbol{T}_{\text {in }} \\
{ }^{\circ} \mathbf{C}\end{array}$ & $\begin{array}{c}\boldsymbol{T}_{\text {out }} \\
{ }^{\mathbf{o}} \mathbf{C}\end{array}$ & $\begin{array}{c}\boldsymbol{T}_{\text {in }}{ }^{*} \\
{ }^{\circ} \mathbf{C}\end{array}$ & $\begin{array}{c}\boldsymbol{T}_{\text {out }}{ }^{*} \\
{ }^{\circ} \mathbf{C}\end{array}$ \\
\hline$i e g$ & Gas & 4.600 & 1379 & 1.11 & 0 & 270 & 380 & 110 & 360 & 90 \\
\hline$i a c$ & Air & 4.485 & 770 & 1.01 & 0 & 170 & 215 & 45 & 195 & 25 \\
\hline$i j w$ & Water & 8.810 & 370 & 4.20 & 0 & 10 & 95 & 85 & 90 & 80 \\
\hline$i l o$ & Oil & 12.381 & 260 & 2.10 & 0 & 10 & 75 & 65 & 70 & 60 \\
\hline
\end{tabular}

Following the methodology described by Linnhoff et al. [19], the information presented in Table 1 was used to calculate the Problem Table depicted in Figure 3, which shows the potential cogenerated heat supplied by the hot flows in each temperature interval. For example, up to $1854 \mathrm{~kW}$ can be recovered at $90{ }^{\circ} \mathrm{C}$, up to $2620 \mathrm{~kW}$ can be recovered at $60{ }^{\circ} \mathrm{C}$, and all the supplied heat $2779 \mathrm{~kW}$ can be recovered at $25^{\circ} \mathrm{C}$. Deploying the total cogenerated heat (heat dissipation is $\left.Q_{d i s}=0 \mathrm{~kW}\right)$ results in a heat efficiency of $\eta_{q}=\left(Q_{g e}-Q_{d i s}\right) / F_{g e}=44.6 \%$, in which case the engine's total energy efficiency reaches $\eta=\eta_{w}+\eta_{q}=91.3 \%$.

\begin{tabular}{|c|c|c|c|c|c|c|c|c|c|c|}
\hline $\begin{array}{c}\text { Temperature } \\
\mathrm{T} \\
\end{array}$ & \begin{tabular}{|c|} 
Interval \\
$\mathrm{k}$ \\
\end{tabular} & 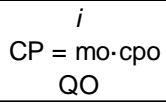 & $\begin{array}{c}\text { ieg } \\
5.106 \mathrm{~kW} / \mathrm{K} \\
1379 \mathrm{~kW} \\
\end{array}$ & $\begin{array}{c}\text { iac } \\
4.529 \mathrm{~kW} / \mathrm{K} \\
770 \mathrm{~kW}\end{array}$ & $\begin{array}{c}\mathrm{ijw} \\
37 \mathrm{~kW} / \mathrm{K} \\
370 \mathrm{~kW} \\
\end{array}$ & $\begin{array}{c}\text { ilo } \\
26 \mathrm{~kW} / \mathrm{K} \\
260 \mathrm{~kW} \\
\end{array}$ & $\begin{array}{l}\Delta \mathrm{T} \\
{[\mathrm{K}]} \\
\end{array}$ & $\begin{array}{c}\Sigma \mathrm{CP} \\
{[\mathrm{kW} / \mathrm{K}]}\end{array}$ & $\begin{array}{c}\text { OK } \\
{[\mathrm{kW}]}\end{array}$ & $\begin{array}{l}\Sigma \mathrm{OK} \\
{[\mathrm{kW}]}\end{array}$ \\
\hline \multirow{2}{*}{$360^{\circ} \mathrm{C}$} & & & & & & & & & & \\
\hline & 1 & & $380^{\circ} \mathrm{C}$ & & & & 165 & 5,106 & 842 & 842 \\
\hline $195^{\circ} \mathrm{C}$ & 2 & & $110^{\circ} \mathrm{C}$ & $215^{\circ} \mathrm{C}$ & & & 105 & 9,635 & 1012 & 1854 \\
\hline $90^{\circ} \mathrm{C}$ & 3 & & & & $\begin{array}{r}95^{\circ} \\
\checkmark 85^{\circ} \\
\end{array}$ & & 10 & 41,529 & 415 & 2270 \\
\hline $80^{\circ} \mathrm{C}$ & 4 & & & & & & 10 & 4,529 & 45 & 2315 \\
\hline $70^{\circ} \mathrm{C}$ & 5 & & & & & $\begin{array}{l}75^{\circ} \mathrm{C} \\
65^{\circ} \mathrm{C}\end{array}$ & 10 & 30,529 & 305 & 2620 \\
\hline $60^{\circ} \mathrm{C}$ & 6 & & & $45^{\circ} \mathrm{C}$ & & & 35 & 4,529 & 159 & 2779 \\
\hline & & & & & & & & & & \\
\hline
\end{tabular}

Figure 3: Problem Table of the gas engine's heat supply.

\subsection{Maximum production of a single energy service}

Given the engine's heat supply, Table 2 shows a list of possible direct thermal energy services that we might be interested in producing, such as hot water at different temperature levels and saturated steam, whose quantities (mass flow $m d$ and energy $Q D$ ) still remain to be determined. 
Table 2: Thermal energy services to be obtained - cold flows $j$.

\begin{tabular}{|c|c|c|c|c|c|c|c|c|c|c|}
\hline Cold flow & Type & $\begin{array}{c}m d \\
\mathrm{~kg} / \mathrm{s}\end{array}$ & $\begin{array}{l}Q D \\
\mathrm{~kW}\end{array}$ & $\begin{array}{c}c p d \\
\mathrm{~kJ} /(\mathrm{kg} \cdot \mathrm{K})\end{array}$ & $\begin{array}{c}\text { lhd } \\
\mathrm{kJ} / \mathrm{kg}\end{array}$ & $\begin{array}{c}\Delta T \\
\mathbf{K}\end{array}$ & $\begin{array}{l}T_{\text {in }} \\
{ }^{\circ} \mathrm{C}\end{array}$ & $\begin{array}{c}T_{o u t} \\
{ }^{\circ} \mathbf{C}\end{array}$ & $\begin{array}{c}T_{\text {in }}{ }^{*} \\
{ }^{o} \mathrm{C}\end{array}$ & $\begin{array}{c}\text { Tout }^{*} \\
{ }^{\circ} \mathrm{C}\end{array}$ \\
\hline jqd & Hot water & $?$ & $?$ & 4.20 & 0 & 40 & 20 & 60 & 20 & 60 \\
\hline jcp & Hot water & $?$ & $?$ & 4.20 & 0 & 5 & 30 & 35 & 30 & 35 \\
\hline juh & Hot water & $?$ & $?$ & 4.20 & 0 & 10 & 35 & 45 & 35 & 45 \\
\hline jas & Hot water & $?$ & $?$ & 4.20 & 0 & 30 & 60 & 90 & 60 & 90 \\
\hline \multirow{2}{*}{ jad } & \multirow{2}{*}{ Saturated steam } & $?$ & $?$ & 4.20 & 0 & 90 & 90 & 180 & 90 & 180 \\
\hline & & $?$ & $?$ & 0 & 2015 & 0 & 180 & 180 & 180 & 180 \\
\hline
\end{tabular}

To assess the maximum production of a single energy service that can be obtained using the engine's heat supply, the OPT was included in a MILP model that imposes the maximum production of said service as the objective function. For example, the maximum production of saturated steam jad is calculated by imposing Max $m d(j a d)$. For each energy service in Table 2, its maximum production $M P$ is shown in Table 3, along with examples of possible applications.

Table 3: Maximum production (MP) of a single energy service.

\begin{tabular}{|c|c|c|c|c|c|c|c|c|}
\hline Application & $\begin{array}{l}\text { Cold } \\
\text { flow }\end{array}$ & $\begin{array}{l}T_{\text {in }} \\
{ }^{\circ} \mathrm{C}\end{array}$ & $\begin{array}{c}\mathrm{T}_{\text {out }} \\
{ }^{\circ} \mathrm{C}\end{array}$ & $\begin{array}{l}\mathrm{md} \\
\mathrm{kg} / \mathrm{s}\end{array}$ & $\begin{array}{l}Q D \\
\mathbf{k W}\end{array}$ & $\begin{array}{l}M P \\
\mathbf{k W}\end{array}$ & $\begin{array}{l}Q_{\text {dis }} \\
\mathbf{k W}\end{array}$ & $\eta_{q} / \eta_{c}$ \\
\hline Domestic hot water & jqd & 20 & 60 & 16.54 & 2779 & 2779 & 0 & $44.6 \%$ \\
\hline Climatized pool & $j c p$ & 30 & 35 & 131.24 & 2756 & 2756 & 23 & $44.3 \%$ \\
\hline Underfloor heating & juh & 35 & 45 & 65.08 & 2733 & 2733 & 45 & $43.9 \%$ \\
\hline Central heating & jas & 60 & 90 & 20.79 & 2620 & 2620 & 158 & $42.1 \%$ \\
\hline Saturated steam & jad & $\begin{array}{c}90 \\
\text { (liq) }\end{array}$ & $\begin{array}{l}180 \\
\text { (sat.) }\end{array}$ & 0.49 & 1172 & 1172 & 1606 & $18.8 \%$ \\
\hline $\begin{array}{l}\text { Cooling (single-effect LiBr } \\
\text { absorption) }\end{array}$ & jas & 60 & 90 & 20.79 & 2620 & $\begin{array}{c}1664 \\
\text { (cooling) }\end{array}$ & 158 & $\begin{array}{r}42.1 \% / \\
26.7 \%\end{array}$ \\
\hline $\begin{array}{l}\text { Cooling (double-effect } \\
\text { LiBr absorption) }\end{array}$ & jad & $\begin{array}{l}90 \\
\text { (liq) }\end{array}$ & $\begin{array}{l}180 \\
\text { (sat.) }\end{array}$ & 0.49 & 1172 & $\begin{array}{c}1653 \\
\text { (cooling) }\end{array}$ & 1606 & $\begin{array}{r}18.8 \% / \\
26.5 \%\end{array}$ \\
\hline
\end{tabular}

The maximum production of domestic hot water with cold flow jqd from 20 to $60{ }^{\circ} \mathrm{C}$ is 2779 $\mathrm{kW}$, which corresponds to the engine's maximum recoverable heat, so that there is no heat dissipation $\left(Q_{d i s}=0 \mathrm{~kW}\right)$ and the heat efficiency is highest $\left(\eta_{q}=44.6 \%\right)$. By contrast, the maximum production of saturated steam jad from 90 to $180^{\circ} \mathrm{C}$ is only $1172 \mathrm{~kW}$, in which case the largest part of the cogenerated heat, corresponding to the heat supplied below $T_{\text {in }}(\mathrm{jad})=90$ ${ }^{\circ} \mathrm{C}$, is dissipated $\left(Q_{d i s}=1606 \mathrm{~kW}\right)$ and the resulting heat efficiency is lowest $\left(\eta_{q}=18.8 \%\right)$. Similar analyses can be made for the maximum individual productions of hot water for climatized pool jcp, underfloor heating juh, and central heating jas, showing that the higher the temperature level required, the greater the heat dissipation and the lower the resulting heat efficiency. These results could also be determined from the diagram shown in Figure 4, which constitutes a graphical tool to assess the heat recovery potential at different temperature levels, indicating, for instance, the maximum individual productions of cold flows jqd, jas, and jad. 
Apart from the direct production of thermal energy services, Table 3 also shows how much cooling could be produced in a single-effect absorption chiller $(\mathrm{COP}=0.635)$ driven by hot water jas or in a double-effect absorption chiller $(\mathrm{COP}=1.41)$ driven by saturated steam jad, and the resulting cooling efficiency $\eta_{c}$. The maximum production of cooling in the single-effect absorption chiller can be determined by imposing the objective function Max 0.635.QD(jas), which results in $1664 \mathrm{~kW}$, with $Q_{d i s}=158 \mathrm{~kW}\left(\eta_{c}=M P(j a s) / F_{g e}=26.7 \%\right)$. Analogously, the maximum production of cooling in the double-effect absorption chiller can be determined by imposing Max 1.41.QD $(\mathrm{jad})$; the result is $1653 \mathrm{~kW}$, with $Q_{\text {dis }}=1606 \mathrm{~kW}\left(\eta_{c}=M P(j a d) / F_{g e}=\right.$ $26.5 \%)$. It is interesting to notice that, even though the amount of cooling produced is virtually the same in both cases, the choice between the single- and the double-effect absorption chiller implies very different heat recovery levels, which will allow to obtain more energy services of low thermal level by choosing double-effect absorption cooling.

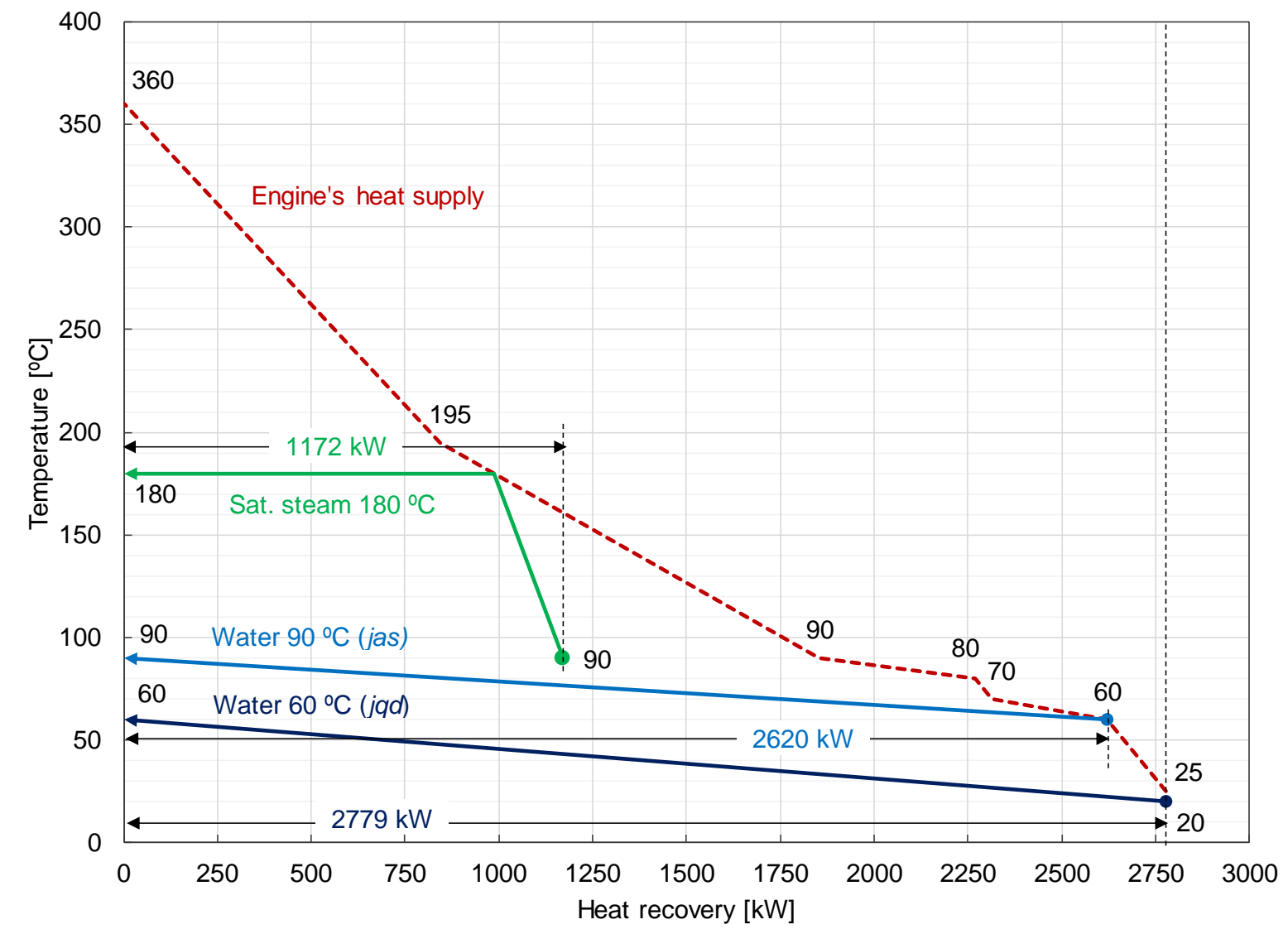

Figure 4: Maximum heat recovery in the production of a single energy service.

The results presented in Table 3 and Figure 4 illustrate the importance of an appropriate thermal characterization of the heat supply and demands in terms of their quantity and temperature levels. The above discussion also makes it clear that the problem of the maximum production of a single thermal energy service is quite simple to solve. In fact, this type of problem could be solved without resorting to the OPT, as demonstrated through Figure 4. That being said, the proposed thermal integration methodology is proven especially useful in more complex situations, such as those when we want to determine the maximum simultaneous production of two or more energy services at different temperature levels. 


\subsection{Maximum simultaneous production of two or more energy services}

For simplicity's sake, let us consider the simultaneous production of only two energy services: saturated steam jad and hot water for central heating jas. Figure 5 shows their maximum simultaneous production, limited on the left by the maximum individual production of steam (square), with $Q D(j a d)=1172 \mathrm{~kW}$ and $m d(j a d)=0.49 \mathrm{~kg} / \mathrm{s}$, and on the right by the maximum individual production of hot water (triangle), with $Q D(j a s)=2620 \mathrm{~kW}$ and $m d(j a s)=20.79$ $\mathrm{kg} / \mathrm{s}$. Following from the explanation provided in the previous section, the maximum individual production of steam leaves a major portion of the engine's heat unused, from which up to $Q D(j a s)=1448 \mathrm{~kW}(m d(j a s)=11.49 \mathrm{~kg} / \mathrm{s})$ of hot water jas can be obtained (dashed line). This solution (circle) corresponds to the maximum heat recovery of the highest quality, that is, the solution that first maximizes steam production and, then, maximizes hot water production with the remaining recoverable heat. Further increasing $Q D(j a s)$ along the solid line necessarily entails reducing $Q D(\mathrm{jad})$. This is clearly an allocation problem, in which a limited resource (cogenerated heat) must be distributed among two or more consumers (energy services). Such distribution, thus, only makes sense provided that a criterion has been established in order to set a value on the different energy services to be produced.

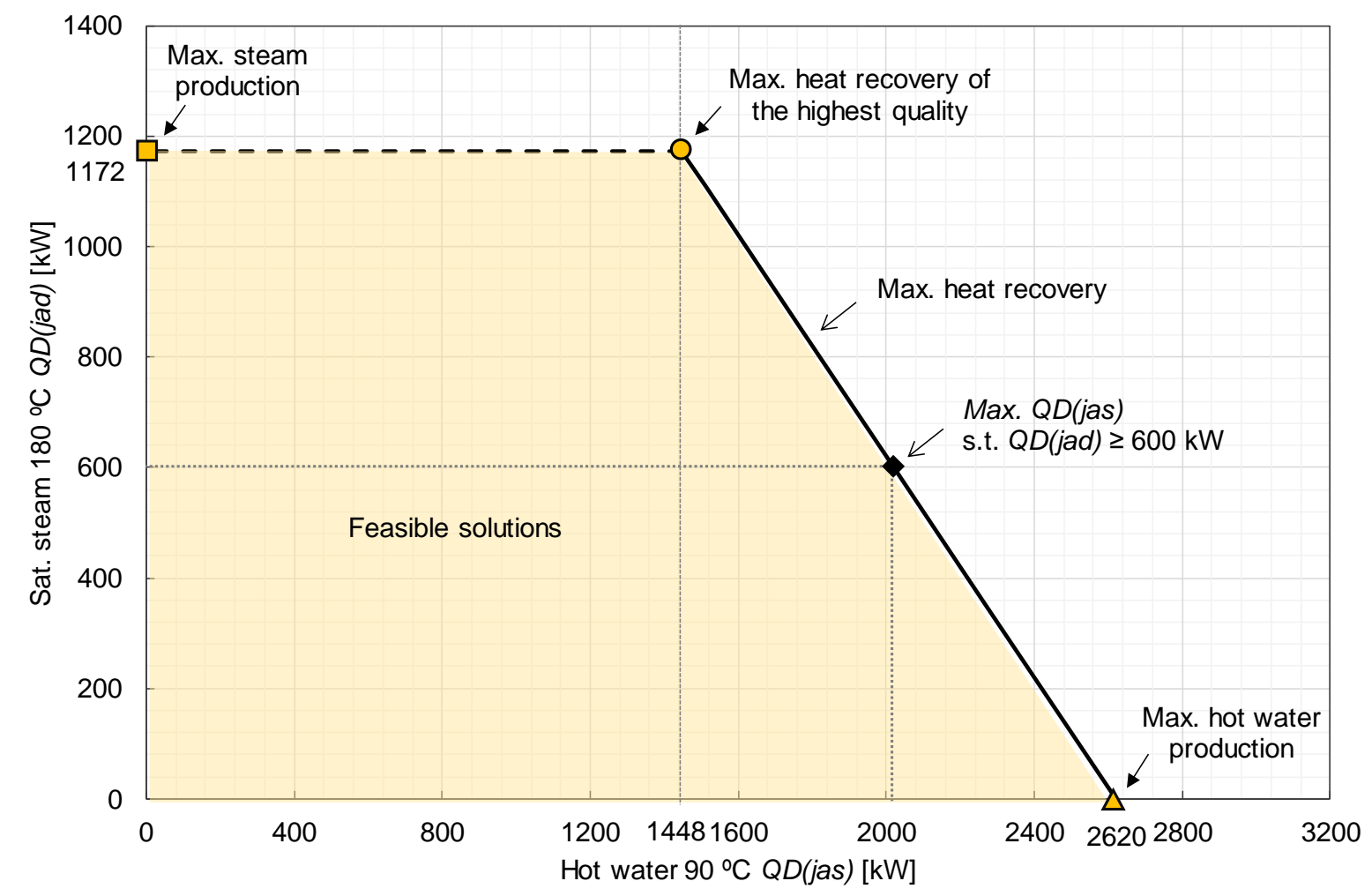

Figure 5: Maximum simultaneous production of saturated steam jad and hot water jas.

So far, the maximum production of energy services has been analyzed only in energy terms. This criterion does not differentiate between the different forms of recovering heat. In this way, the objective function Max $[Q D(j a s)+Q D(j a d)]$ yields $2620 \mathrm{~kW}$, which corresponds to any combination of $Q D(j a s)$ and $Q D(j a d)$ contained in the solid line of Figure 5. While these solutions are all equivalent in energy terms (they all reach the maximum heat recovery of 2620 
$\mathrm{kW}$ ), each of them allows for very different applications, such as cooling production in singleor double-effect absorption chillers as will be discussed later. Therefore, a criterion other than energy must be established to make sure that the different products are properly valued.

The thermodynamic value of an energy service is precisely represented in terms of exergy. The exergy content $B D(j)$ of an energy flow (e.g. cold flow $j$ ) can be calculated as

$$
\begin{array}{r}
B D(j)=\dot{m d}(j) \cdot \operatorname{lhd}(j) \cdot\left(1-\frac{T_{0}}{T_{m}(j)}\right)+\dot{m d}(j) \cdot \operatorname{cpd}(j) \\
\cdot\left[T_{\text {out }}(j)-T_{\text {in }}(j)-T_{0} \cdot \ln \left(\frac{T_{\text {out }}(j)}{T_{\text {in }}(j)}\right)\right]
\end{array}
$$

where $T_{0}$ is the reference ambient temperature $293 \mathrm{~K}, T_{m}(j)$ is the phase change temperature, if applicable, and the temperatures $T_{m}(j), T_{\text {in }}(j)$ and $T_{\text {out }}(j)$ are given in Kelvin. The objective function is thus formulated as $\operatorname{Max}[B D(j a s)+B D(j a d)]$. The optimal result is $628 \mathrm{~kW}$, with $B D(j a s)=228 \mathrm{~kW}(m d(j a s)=11.49 \mathrm{~kg} / \mathrm{s})$ and $B D(j a d)=400 \mathrm{~kW}(m d(j a d)=0.49 \mathrm{~kg} / \mathrm{s})$, which corresponds to the point of maximum heat recovery of the highest quality in Figure 5 (circle). This solution is reached since saturated steam has a higher exergetic value than hot water.

The economic cost of a mass or energy flow is also an important criterion to place a value on the recoverable heat since the feasibility of a project is commonly evaluated based on its economic performance. Assuming that the facility in which the engine is installed receives 0.05 $€ / \mathrm{kWh}$ and $0.08 € / \mathrm{kWh}$ of hot water and steam produced, respectively, the objective function of the OPT Max $[0.05 \cdot Q D(j a s)+0.08 \cdot Q D(j a d)]$ results in $166.2 € / \mathrm{h}$, with $m d(j a s)=11.49 \mathrm{~kg} / \mathrm{s}$ and $m d(j a d)=0.49 \mathrm{~kg} / \mathrm{s}$. As can be seen, this solution also corresponds to the maximum heat recovery of the highest quality, since saturated steam has a higher economic value than hot water.

Addressing the problem from a different angle, instead of directly maximizing the simultaneous productions of hot water jas and saturated steam jad, now the goal is to determine the maximum amount of cooling that can be produced from these flows in a single-effect $(\mathrm{COP}=0.635)$ and in a double-effect $(\mathrm{COP}=1.41)$ absorption chillers. The objective function is formulated as $\operatorname{Max}[0.635 \cdot Q D(j a s)+1.41 \cdot Q D(j a d)]$, which results in $2572 \mathrm{~kW}$ of cooling, with the same combination of $m d(j a s)$ and $m d(j a d)$ as those of the exergy and economic optimal solutions. It is noteworthy that, even though the double-effect absorption chiller is the preferred choice to maximize cooling production efficiently for its higher COP, this device also requires high quality thermal energy; therefore, the OPT first maximizes steam jad production in the doubleeffect chiller and then hot water jas production in the single-effect chiller with the remaining heat.

The maximum simultaneous production problem can also be tackled through production constraints in the OPT. For example, it can be proposed as an objective function to obtain the maximum production of hot water jas with a specified production of steam jad. For this, the objective function of the OPT is defined as Max $Q D(j a s)$, with the additional constraint $Q D(j a d)$ $\geq q x$. With $q x=600 \mathrm{~kW}$, the result is $Q D(j a s)=2020 \mathrm{~kW}$ (rhombus in Figure 5). 
The solutions highlighted in Figure 5 are compared in Figure 6 based on their energy $Q D$ and exergy $B D$ contents and their total energy $\eta$ and exergy $\varepsilon$ efficiencies. The exergy efficiency $\varepsilon$ is calculated as

$\varepsilon=\frac{W_{g e}+B D}{F_{g e}^{b}}$

where $F_{g e}^{b}=6444 \mathrm{~kW}$ is the exergy content of the natural gas consumed by the engine, obtained by multiplying its energy content $F_{g e}=6225 \mathrm{~kW}$ by the ratio of its specific exergy $39,330 \mathrm{~kJ} / \mathrm{kg}$ to its lower heating value $37,991 \mathrm{~kJ} / \mathrm{kg}$.

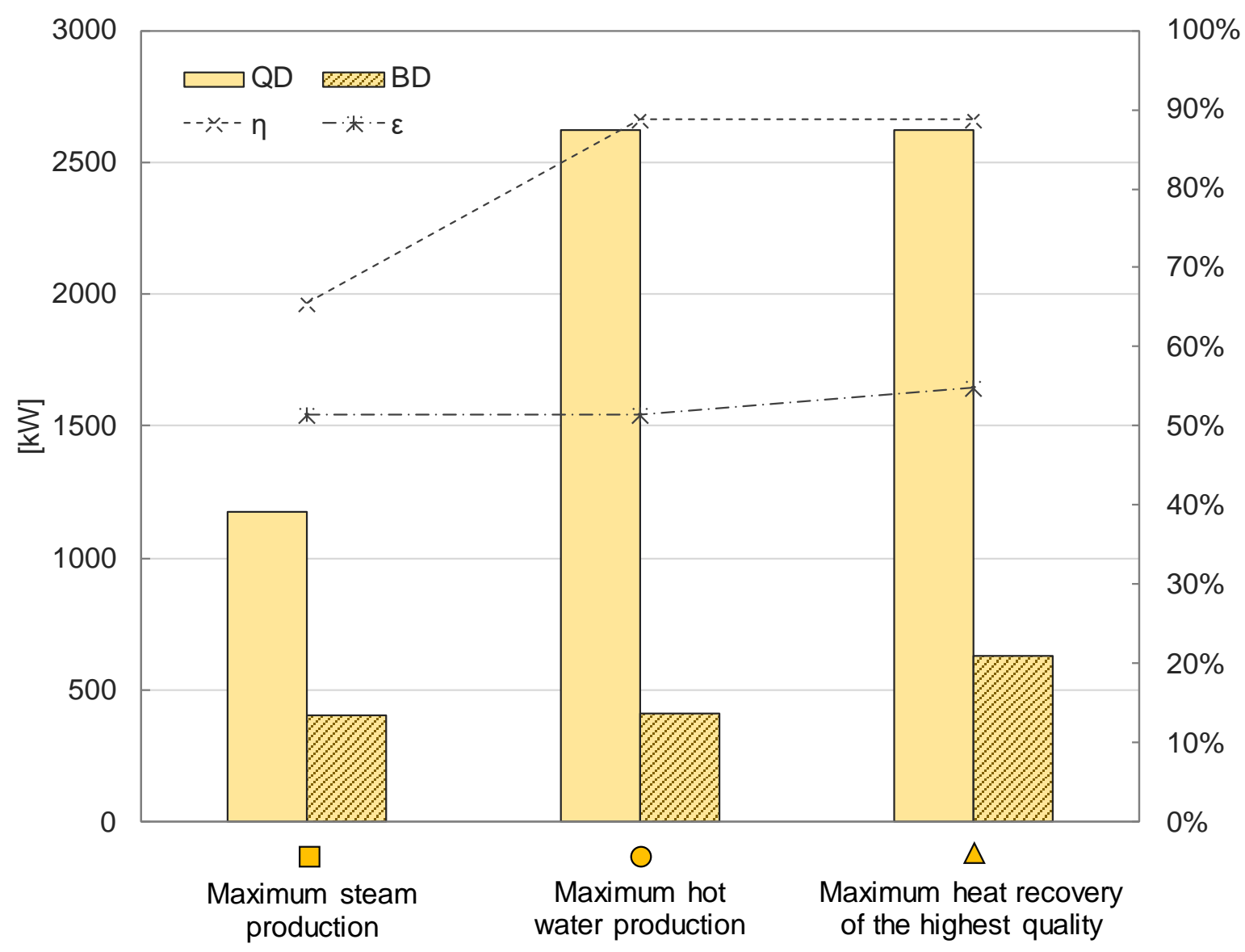

Figure 6: Comparison between different solutions from energy and exergy viewpoints.

The results presented in this section have shown that there are multiple feasible ways of simultaneously producing two or more energy services from a limited energy resource (e.g. cogenerated heat). In this way, a systematic procedure is required for the heat recovery to make practical sense. The next step is to consider the time dimension, which had been omitted until now, allowing the operation of the engine to adjust in each time interval to the varying thermal energy demands.

\subsection{Maximum heat recovery for variable energy demands}


Until now it has been considered that the engine operated at constant nominal load. Now, the following considerations will be made: (i) the consumer center imposes the thermal energy demands, which vary over time; and (ii) the engine must adjust its operation load to meet the energy requirements with minimum heat dissipation.

In order to allow for partial load operation in the OPT it is necessary to connect the recoverable heat to the engine's operating capacity. Thus, the hot flow's mass rate $m o(i, \theta)$, which was initially given as input data in Table 1 , is now expressed as

$\operatorname{mo}(i, \theta)=\operatorname{mou}(i) \cdot \operatorname{OPECAP}(\theta)$

where $\operatorname{mou}(i)$ is the unit mass flow rate of the hot flow $i$ per $\mathrm{kW}$ of installed power capacity and $\operatorname{OPECAP}(\theta)$ is the partial operating load of the engine in the time period $\theta$.

The $m o u(i)$ values are obtained by dividing the mo initially given in Table 1 by the engine's net electric power capacity $2910 \mathrm{~kW}: \operatorname{mou}($ ieg $)=1.5808 \cdot 10^{-3}(\mathrm{~kg} / \mathrm{s}) / \mathrm{kW}, \operatorname{mou}($ iac $)=1.5394 \cdot 10^{-3}$ $(\mathrm{kg} / \mathrm{s}) / \mathrm{kW}, \operatorname{mou}(i j w)=3.0240 \cdot 10^{-3}(\mathrm{~kg} / \mathrm{s}) / \mathrm{kW}$, and $\operatorname{mou}(i l o)=4.2612 \cdot 10^{-3}(\mathrm{~kg} / \mathrm{s}) / \mathrm{kW}$. In each time period $\theta$, the $\operatorname{OPECAP}(\theta)$ must be lower than or equal to the engine's installed power capacity:

$O P E C A P(\theta) \leq 2910 \mathrm{~kW}$

An illustrative example is developed below to demonstrate the application of the updated OPT. A small industrial facility requires hot water jas and steam jad in three operating periods, as shown in Table 4 (heat demand). The aim is to deploy the gas engine to meet the thermal energy demands in each time period with minimum heat dissipation. The objective function of the OPT is formulated as $\operatorname{Min} \sum Q_{d i s}(\theta)$. The main results are presented in Table 4 (heat supply) and Figure 7.

Table 4: Heat supply and demand in three time periods.

\begin{tabular}{|c|r|r|r|r|r|r|r|r|}
\hline \multirow{2}{*}{$\begin{array}{c}\text { Period } \\
\theta\end{array}$} & \multicolumn{2}{|c|}{ Heat demand } & \multicolumn{1}{|c|}{ Heat supply } \\
\cline { 2 - 9 } & $\begin{array}{c}\text { QD(jas) } \\
\mathbf{k W}\end{array}$ & $\begin{array}{c}\text { QD(jad) } \\
\mathbf{k W}\end{array}$ & $\begin{array}{c}\text { OPECAP } \\
\mathbf{k W}\end{array}$ & $\begin{array}{c}\text { QO(ieg) } \\
\mathbf{k W}\end{array}$ & $\begin{array}{c}\text { QO(iac) } \\
\mathbf{k W}\end{array}$ & $\begin{array}{c}\boldsymbol{Q} \text { OO(ijw) } \\
\mathbf{k W}\end{array}$ & $\begin{array}{c}\boldsymbol{Q} \text { OO(ilo) } \\
\mathbf{k W}\end{array}$ & $\begin{array}{c}\boldsymbol{Q}_{\text {dis }} \\
\mathbf{k W}\end{array}$ \\
\hline 1 & 2000 & 250 & 2498.8 & 1184.0 & 661.2 & 317.7 & 223.3 & 136.1 \\
\hline 2 & 1175 & 950 & 2350.0 & 1118.2 & 624.4 & 300.0 & 210.9 & 128.6 \\
\hline 3 & 450 & 1150 & 2854.8 & 1352.6 & 755.3 & 362.9 & 255.1 & 1125.8 \\
\hline
\end{tabular}




\begin{tabular}{|c|c|c|c|c|c|c|c|c|c|c|c|c|c|c|c|c|}
\hline \multirow[b]{2}{*}{$\begin{array}{c}\text { Temperature } \\
\mathrm{T} \\
\end{array}$} & \multirow[b]{2}{*}{$\begin{array}{c}\text { Interval } \\
\mathrm{k} \\
\end{array}$} & \multicolumn{4}{|c|}{ Heat supply } & \multicolumn{2}{|c|}{ Heat demand } & \multicolumn{3}{|c|}{ Period 1} & \multicolumn{3}{|c|}{ Period 2} & \multicolumn{3}{|c|}{ Period 3} \\
\hline & & QO(ieg) & QO(iac) & QO(ijw) & QO(ilo) & $\mathrm{QD}$ (jas) & $\mathrm{QD}(\mathrm{jad})$ & $\begin{array}{c}\mathrm{OK} \\
{[\mathrm{kW}]}\end{array}$ & $\begin{array}{c}\text { DK } \\
{[k W]}\end{array}$ & $\begin{array}{c}\mathrm{RK} \\
{[\mathrm{kW}]}\end{array}$ & $\begin{array}{c}\mathrm{OK} \\
{[\mathrm{kW}]}\end{array}$ & $\begin{array}{c}\text { DK } \\
{[\mathrm{kW}]}\end{array}$ & $\begin{array}{c}\mathrm{RK} \\
{[\mathrm{kW}]}\end{array}$ & $\begin{array}{c}\mathrm{OK} \\
{[\mathrm{kW}]}\end{array}$ & $\begin{array}{c}\mathrm{DK} \\
{[\mathrm{kW}]}\end{array}$ & $\begin{array}{c}\mathrm{RK} \\
{[\mathrm{kW}]}\end{array}$ \\
\hline $360^{\circ} \mathrm{C}$ & (1) & $380^{\circ}$ & & & & & & 724 & 0 & 724 & 683 & 0 & 683 & 827 & 0 & 827 \\
\hline $195^{\circ} \mathrm{C}$ & (2) & & $215^{\circ}$ & & & & & 124 & 0 & 848 & 117 & 0 & 801 & 142 & 0 & 968 \\
\hline $180^{\circ} \mathrm{C}(+)$ & (3) & & & & & & & 0 & 211 & 637 & 0 & 800 & 1 & 0 & 968 & 0 \\
\hline $180^{\circ} \mathrm{C}(-)$ & (4) & $410^{\circ}$ & & & & & & 745 & 39 & 1342 & 703 & 150 & 554 & 851 & 182 & 669 \\
\hline $90^{\circ} \mathrm{C}$ & (5) & & & $\begin{array}{l}95^{\circ} \mathrm{C} \\
85^{\circ} \mathrm{C}\end{array}$ & & & & 357 & 667 & 1032 & 337 & 392 & 499 & 407 & 150 & 926 \\
\hline $80^{\circ} \mathrm{C}$ & (6) & & & & & & & 39 & 667 & 404 & 37 & 392 & 144 & 44 & 150 & 821 \\
\hline $70^{\circ} \mathrm{C}$ & (7) & & & & $\begin{array}{r}75^{\circ} \mathrm{C} \\
65^{\circ} \mathrm{C} \\
\end{array}$ & & & 262 & 667 & 0 & 248 & 392 & 0 & 299 & 150 & 970 \\
\hline $60^{\circ} \mathrm{C}$ & (8) & & $45^{\circ} \mathrm{C}$ & & & & & 136 & 0 & 136 & 129 & 0 & 129 & 155 & 0 & 1126 \\
\hline
\end{tabular}

Figure 7: Problem table for hot water jas and steam jad production in three time periods.

The analysis of the optimal operation of the gas engine in each operating period sheds light on the different ways the heat recovery is adjusted to the thermal energy demands' quantity and quality levels. This is evinced by the shift in the pinch point from one temperature interval to another in different operating periods, indicated by $R K(k, \theta)=0 \mathrm{~kW}$, as can be seen in Figure 7 . For example, in operating period 1 the heat recovery is constrained by the hot water demand $Q D$ (jas), as indicated by the pinch point at $60^{\circ} \mathrm{C}$, between temperature intervals 7 and 8 , so that the heat supplied to temperature intervals 1 to 7 is entirely consumed by the cold flows; $Q_{\text {dis }}(1)$ is the low-temperature heat supplied to $k=8$ that cannot be feasibly recovered. By contrast, in operating period 3 the heat recovery is constrained by the steam demand $Q D(j a d)$ and the pinch point takes place at $180^{\circ} \mathrm{C}$, between temperature intervals 3 and 4 . In operating period 2 the $Q D(j a s)$ and $Q D(j a d)$ are balanced, so two pinch points are suggested, one at $180^{\circ} \mathrm{C}$ and another at $60{ }^{\circ} \mathrm{C}$.

Clearly, the shifting pinch points represent a challenge to the design of the heat exchanger network that must be dealt with accordingly. However, this is beyond the scope of this study, in which a virtual heat exchanger network is considered.

As has been seen, the OPT provides great flexibility to the optimal match between the heat supply and the heat demand regarding quantity and quality (temperature) levels. In the next section, a different situation is posed in which the OPT is applied to the synthesis of a polygeneration system.

\section{Application in the synthesis problem: Case study}

To show the applicability of the proposed OPT in the synthesis problem, a case study will be solved. The reader is referred to Pina [54] for an in-depth description of the case study data, the technical and economic data, and the mathematical model developed.

\subsection{The Brazilian university hospital}


The case study corresponds to a medium-size university hospital with 403 beds and 65,000 $\mathrm{m}^{2}$ constructed area, located in the city of Campinas, in the southeastern region of Brazil. The hospital's energy demand data have been originally presented by Santo [55]. The analysis has been carried out for the period of one year, divided into 24 representative days $d$ (one working day $w d$ and one weekend/holiday we for each month of the year), each one composed of 24 consecutive periods $h$ of 1 hour. The number of representative days type $d$ per year $N R Y(d)$ is shown in Table 5.

Table 5: Number of representative days type $d$ per year $N R Y(d)$.

\begin{tabular}{|c|r|r|r|r|r|r|r|r|r|r|r|r|}
\hline Day & Jan & Feb & Mar & Apr & May & Jun & Jul & Aug & Sep & Oct & Nov & Dec \\
\hline$w d$ & 21 & 19 & 22 & 20 & 20 & 21 & 23 & 21 & 21 & 21 & 19 & 22 \\
\hline$w e$ & 10 & 9 & 9 & 10 & 11 & 9 & 8 & 10 & 9 & 10 & 11 & 9 \\
\hline
\end{tabular}

The energy demands that the polygeneration system must attend are electricity for lighting, elevators and other services, saturated steam at $180{ }^{\circ} \mathrm{C}$ for cooking, laundry and sterilization, hot water at $60{ }^{\circ} \mathrm{C}$ for sanitary purposes, and chilled water at $7{ }^{\circ} \mathrm{C}$ for air conditioning. It is noteworthy that the electricity demand does not account for the consumption for thermal energy production, such as electricity consumption to produce cooling in mechanical chillers driven by electric motors.

The annual energy demand of electricity is $9,633.5 \mathrm{MWh}$, hot water is $518.7 \mathrm{MWh}$, steam is 4,660.3 MWh, and chilled water is 4,755.7 MWh. The energy demand profiles are available on hourly basis for a working day $w d$ and a weekend/holiday we of each season: summer (from January to March), autumn (from April to June), winter (from July to September) and spring (from October to December). The daily energy demands of the hospital are shown in Table 6. Figure 8 presents two examples of the hourly energy demands of a working day in summer (when electricity and cooling demands are highest) and in winter (when hot water demand is highest).

Table 6: Hospital's daily energy demands per season, in kWh [55].

\begin{tabular}{|c|c|c|c|c|c|c|c|c|}
\hline \multirow{2}{*}{$\begin{array}{l}\text { Energy } \\
\text { demand }\end{array}$} & \multicolumn{2}{|c|}{$\begin{array}{c}\text { Summer } \\
\text { (Jan-Mar) }\end{array}$} & \multicolumn{2}{|c|}{$\begin{array}{c}\text { Autumn } \\
\text { (Apr-Jun) }\end{array}$} & \multicolumn{2}{|c|}{$\begin{array}{c}\text { Winter } \\
\text { (Jul-Sep) }\end{array}$} & \multicolumn{2}{|c|}{$\begin{array}{c}\text { Spring } \\
\text { (Oct-Dec) }\end{array}$} \\
\hline & $\begin{array}{c}\text { Working } \\
\text { day } w d\end{array}$ & $\begin{array}{c}\text { Weekend } \\
\text { we }\end{array}$ & $\begin{array}{c}\text { Working } \\
\text { day } w d\end{array}$ & $\begin{array}{c}\text { Weekend } \\
\text { we }\end{array}$ & $\begin{array}{l}\text { Working } \\
\text { day } w d\end{array}$ & $\begin{array}{c}\text { Weekend } \\
\text { we }\end{array}$ & $\begin{array}{c}\text { Working } \\
\text { day } w d\end{array}$ & $\begin{array}{c}\text { Weekend } \\
\text { we }\end{array}$ \\
\hline $\begin{array}{c}\text { Electricity } \\
E_{d}\end{array}$ & 31,614 & 25,503 & 27,262 & 21,384 & 25,375 & 20,840 & 28,273 & 22,996 \\
\hline Steam $V_{d}$ & 16,257 & 15,037 & 10,947 & 11,858 & 10,393 & 12,868 & 12,236 & 14,206 \\
\hline $\begin{array}{c}\text { Hot water } \\
Q_{d}\end{array}$ & 1,178 & 889 & 1,788 & 1,077 & 2,039 & 1,225 & 1,438 & 822 \\
\hline $\begin{array}{c}\text { Chilled } \\
\text { water } R_{d}\end{array}$ & 18,321 & 16,412 & 12,116 & 11,580 & 8,424 & 7,896 & 14,788 & 13,205 \\
\hline
\end{tabular}



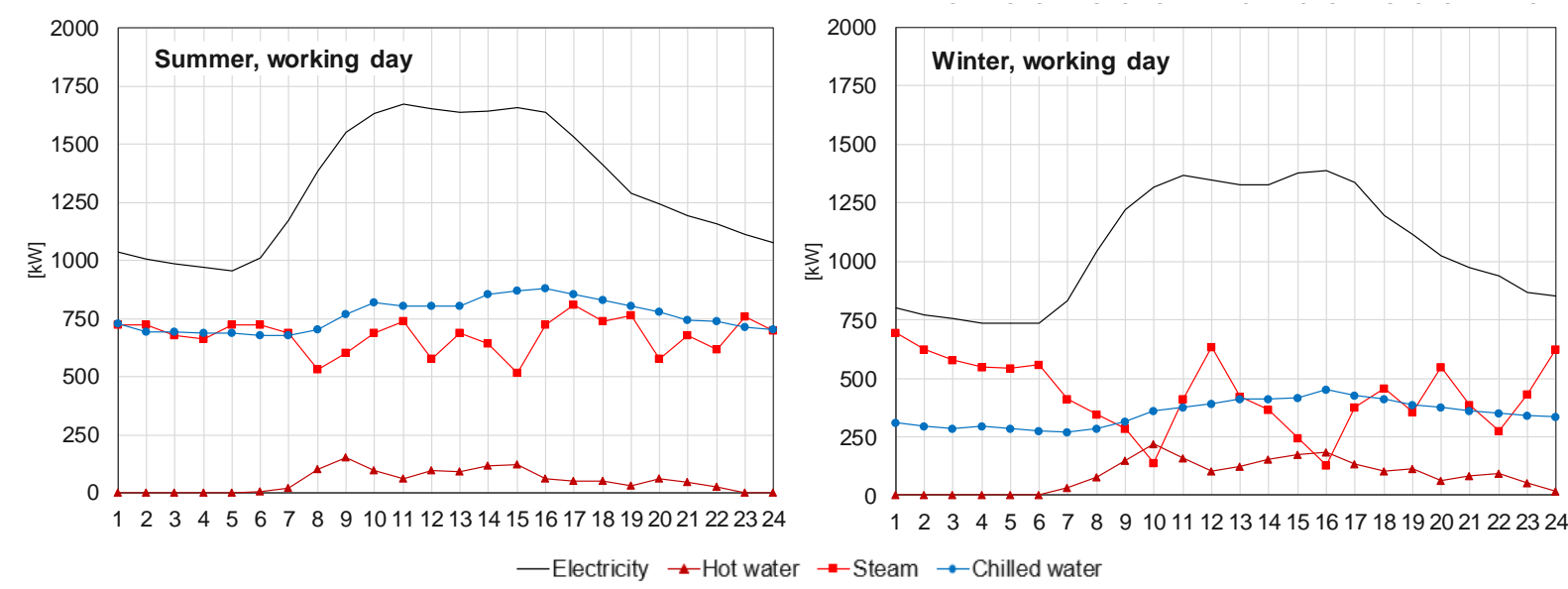

Figure 8: Hourly energy demands of a working day in the summer (left) and in the winter (right) [55].

Local energy prices are required for the assessment of the system's operating costs. Natural gas is purchased at $p_{\text {gas }}=0.035 € / \mathrm{kWh}$ (LHV) (including taxes) [56]. In the case of electricity, the purchase price $p_{e p}$ varies according to the hour of the day and the month of the year in two billing periods, as shown in Table 7. The electricity selling price $p_{e s}$ was assumed to be the purchase price at the corresponding hour minus a penalization of penven $=0.012 € / \mathrm{kWh}$, which accounts for the Tariff of Use of Distribution System relative to distribution and availability costs [57].

Table 7: Hourly electricity purchase price (with taxes).

\begin{tabular}{|c|c|c|c|c|}
\hline \multirow{2}{*}{ Annual period } & \multicolumn{2}{|c|}{ On-peak } & \multicolumn{2}{c|}{ Off-peak } \\
\cline { 2 - 5 } & Hours & $\boldsymbol{p}_{\boldsymbol{e}}$ & Hours & $\boldsymbol{p}_{\text {ep }}$ \\
\hline March to October & $18-20$ & $0.136 € / \mathrm{kWh}$ & $1-17,21-24$ & $0.094 € / \mathrm{kWh}$ \\
\hline November to February & $19-21$ & $0.136 € / \mathrm{kWh}$ & $1-18,22-24$ & $0.094 € / \mathrm{kWh}$ \\
\hline
\end{tabular}

\subsection{Superstructure and technical-economic data}

The superstructure of the polygeneration system is depicted in Figure 9. The available energy resources include natural gas and electricity purchased from the electric grid. The system is designed to cover the hospital's energy demands. It is assumed that both electricity purchase and sale are allowed. The candidate technologies can be divided into three categories:

- Generation technologies: Cogeneration module GE, hot water gas boiler GH, and steam gas boiler GV. Convert the energy resource into intermediate or final products.

- Transformation technologies: Mechanical chiller EC, single-effect absorption chiller $\mathrm{AS}$, and double-effect absorption chiller $\mathrm{AD}$. Convert the energy resource or intermediate product into a final product.

- Heat dissipation technology: Cooling tower CT. Dissipate to the environment the heat discarded by the transformation technologies (EC, AS, AD) and the thermal integration subsystem. 


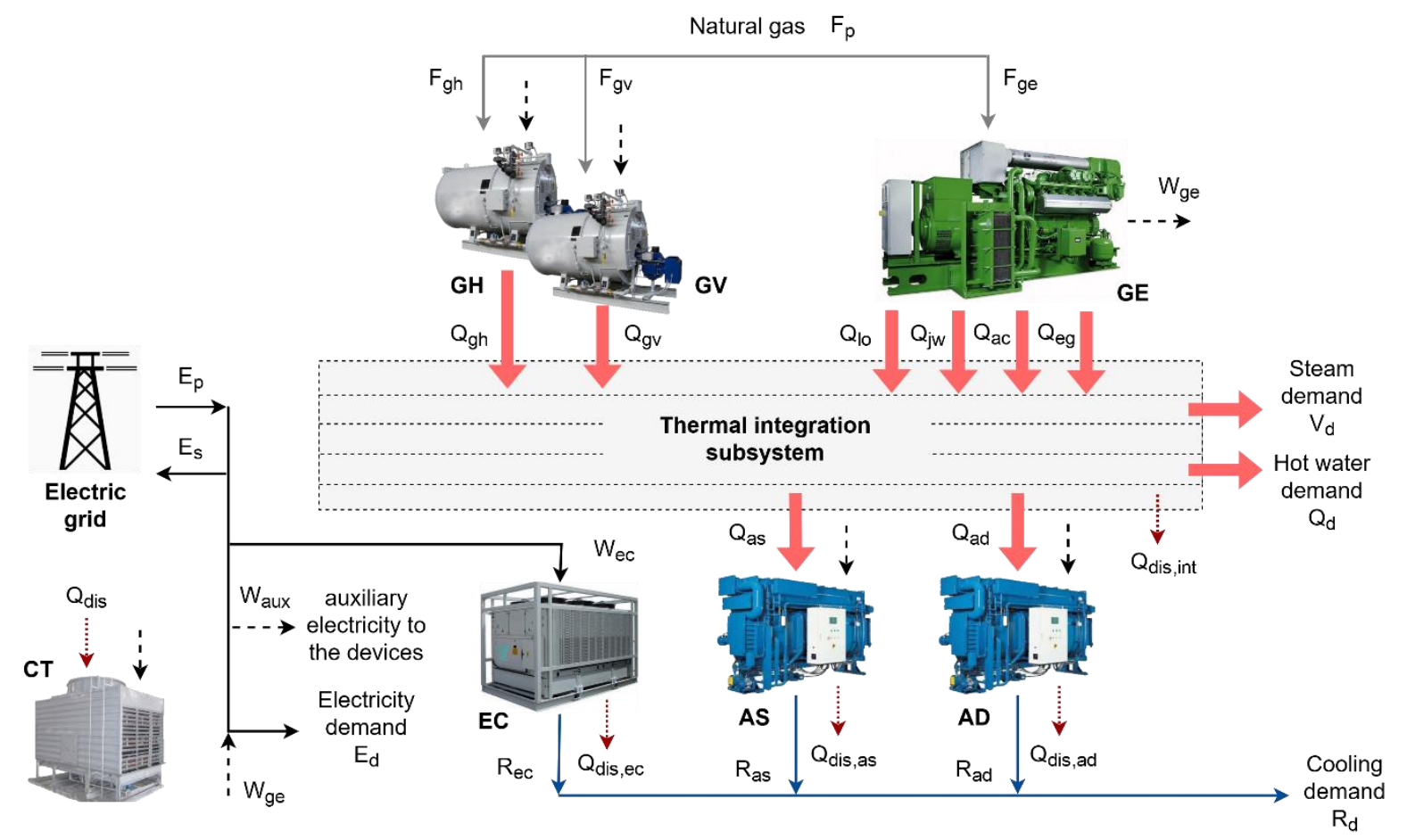

Figure 9: Superstructure of the polygeneration system.

The generation technologies supply heat to the thermal integration subsystem, which can be used to produce the steam and hot water demands of the hospital, as well as to drive the absorption chillers. An auxiliary electricity consumption was considered for most technologies.

The candidate technologies are based on real, commercially available devices. In particular, the cogeneration module is based on the one presented in Section 3. The technical data correspond to a representative device that was carefully selected to fit within the capacity range estimated based on the hospital's energy demands. Table 8 shows the main technical parameters of the technologies, as described by Pina [54], including the electric and/or thermal (LHV) efficiencies $\eta$, coefficient of performance $C O P$, and the unit auxiliary electricity consumption $C U e$.

The economic cost of installing the technologies is given by the bare module cost $C I$, also shown in Table 8, obtained from Ramos [15]. The CI corresponds to the purchase cost multiplied by a simple module factor, which accounts for transportation, installation, connection costs, etc. Additional economic data include amortization and maintenance factor fam $=0.15 \mathrm{yr}^{-1}$ and the indirect costs factor $f_{I C}=0.20$ [15]. The plant's operational lifetime $n y r$ is 20 years.

The thermal integration subsystem outlined in Figure 9 implements the OPT described in Section 2, which allows the hot flows supplied by the generation technologies and the cold flows consumed by transformation technologies and/or associated with the thermal energy demands of the consumer center to exchange heat through a virtual network of heat exchangers. The thermal integration subsystem thus serves as interface between the heat supply and the heat demand in the system. 
Table 8: Technical and economic parameters of the candidate technologies.

\begin{tabular}{|c|c|c|c|c|c|}
\hline Technology & $\begin{array}{c}\text { Efficiency, } \\
\eta\end{array}$ & $\begin{array}{c}\text { Coefficient of } \\
\text { Performance, } \\
\text { COP }\end{array}$ & $\begin{array}{c}\text { Unit } \\
\text { auxiliary } \\
\text { electricity } \\
\text { consumption, } \\
\text { CUe, } \\
\mathbf{k W} \mathbf{e} / \mathbf{k W}\end{array}$ & $\begin{array}{c}\text { Maximum } \\
\text { installable } \\
\text { capacity, } \\
P I N_{M A X} \\
\text { kW }\end{array}$ & $\begin{array}{c}\text { Bare } \\
\text { module } \\
\text { cost, } \\
C I, € / \mathbf{k W}\end{array}$ \\
\hline GE Cogeneration module & $0.467^{*}$ & - & 0.030 & 5000 & 675 \\
\hline GV Steam boiler & 0.930 & - & 0.005 & 5000 & 120 \\
\hline GH Hot water boiler & 0.920 & - & 0.005 & 5000 & 55 \\
\hline EC Electric chiller & - & 6.110 & - & 5000 & 105 \\
\hline $\begin{array}{l}\text { AS Single-effect absorption } \\
\text { chiller }\end{array}$ & - & 0.635 & 0.005 & 5000 & 260 \\
\hline $\begin{array}{l}\text { AD Double-effect absorption } \\
\text { chiller }\end{array}$ & - & 1.410 & 0.005 & 5000 & 260 \\
\hline CT Cooling tower & 1.000 & - & 0.005 & 10,000 & 30 \\
\hline
\end{tabular}

electric efficiency.

Following a similar procedure to that of Section 3, hot $i$ and cold $j$ flows were identified based on the heat sources and demands of the candidate technologies in the superstructure and characterized in terms of their thermal properties. Moreover, the same minimum temperature differences were considered to promote the heat exchange, namely $20{ }^{\circ} \mathrm{C}$ in the case of gas flows (e.g. exhaust gas, air) and $5{ }^{\circ} \mathrm{C}$ in the case of liquid flows (e.g. water, oil). As it was decided to maintain the temperatures of the thermal energy services supplied to the consumer center unchanged, the minimum temperature differences have been carried out to the hot flows.

Table 9 presents the thermal characteristics of the different hot flows, in which the unit mass flow rate $m o u(i)$ is given in $\mathrm{kg} / \mathrm{s}$ per $\mathrm{kW}$ of operating capacity of the technology that supply the flow. Apart from the GE's flows (ieg, iac, ijw, and ilo) explained in Section 0, the GH supplies hot water at $95^{\circ} \mathrm{C}$ from hot water at $75^{\circ} \mathrm{C}$ (flow igh) and the $\mathrm{GV}$ supplies saturated steam at $185^{\circ} \mathrm{C}$ from hot water at $95^{\circ} \mathrm{C}$ (flow igv).

Table 9: Thermal characteristics of the hot flows $i$.

\begin{tabular}{|c|c|c|c|c|c|c|c|c|c|c|}
\hline $\begin{array}{c}\text { Tech. } \\
\boldsymbol{t}\end{array}$ & Hot flow & Type & $\begin{array}{c}\mathbf{m o u} \\
(\mathbf{k g} / \mathbf{s}) / \mathbf{k W}\end{array}$ & $\begin{array}{c}\mathbf{c p o} \\
\mathbf{k J} /(\mathbf{k g} \cdot \mathbf{K})\end{array}$ & $\begin{array}{c}\text { lho } \\
\mathbf{k J} / \mathbf{k g}\end{array}$ & $\begin{array}{c}\Delta T \\
\mathbf{K}\end{array}$ & $\begin{array}{c}\boldsymbol{T}_{\text {in }} \\
{ }^{\circ} \mathbf{C}\end{array}$ & $\begin{array}{c}\boldsymbol{T}_{\text {out }} \\
{ }^{\circ} \mathbf{C}\end{array}$ & $\begin{array}{c}\boldsymbol{T}_{\text {in }}{ }^{*} \\
{ }^{\circ} \mathbf{C}\end{array}$ & $\begin{array}{c}\boldsymbol{T}_{\text {out }}{ }^{*} \\
{ }^{\circ} \mathbf{C}\end{array}$ \\
\hline GE & $i e g$ & Gas & $1.5808 \cdot 10^{-3}$ & 1.110 & 0 & 270 & 380 & 110 & 360 & 90 \\
\hline GE & $i a c$ & Air & $1.5394 \cdot 10^{-3}$ & 1.010 & 0 & 170 & 215 & 45 & 195 & 25 \\
\hline GE & $i j w$ & Water & $3.0240 \cdot 10^{-3}$ & 4.200 & 0 & 10 & 95 & 85 & 90 & 80 \\
\hline GE & $i l o$ & Oil & $4.2612 \cdot 10^{-3}$ & 2.100 & 0 & 10 & 75 & 65 & 70 & 60 \\
\hline GH & $i g h$ & Water & $11.9048 \cdot 10^{-3}$ & 4.200 & 0 & 20 & 95 & 75 & 90 & 70 \\
\hline GV & $i g v$ & Water & $0.4179 \cdot 10^{-3}$ & 4.200 & 2015 & 90 & 185 & 95 & 180 & 90 \\
\hline
\end{tabular}

The thermal characteristics of the cold flows are shown in Table 10, in which the unit mass flow rate $m d u(j)$ is given in $\mathrm{kg} / \mathrm{s}$ per $\mathrm{kW}$ of operating capacity of the technology that consumes the flow in the case of the absorption chillers (flows jas and jad), and in $\mathrm{kg} / \mathrm{s}$ per $\mathrm{kW}$ of energy service consumed in the case of the hospital's steam (flow jvd) and hot water (flow jqd) demands. The cold flows jas, jad, and jqd were explained in Section 3.1. Additionally, the flow 
$j v d$ corresponds to the hospital's saturated steam demand at $180{ }^{\circ} \mathrm{C}$ that returns as hot water at $70{ }^{\circ} \mathrm{C}$.

Table 10: Thermal characteristics of the cold flows $j$.

\begin{tabular}{|c|c|c|c|c|c|c|c|c|c|c|}
\hline $\begin{array}{c}\text { Tech. } \\
\boldsymbol{t}\end{array}$ & $\begin{array}{c}\text { Cold } \\
\text { flow }\end{array}$ & Type & $\begin{array}{c}\boldsymbol{m d u} \\
(\mathbf{k g} / \mathbf{s}) / \mathbf{k W}\end{array}$ & $\begin{array}{c}\boldsymbol{c p d} \\
\mathbf{k J} /(\mathbf{k g} \cdot \mathbf{K})\end{array}$ & $\begin{array}{c}\boldsymbol{l h d} \\
\mathbf{k J} / \mathbf{k g}\end{array}$ & $\begin{array}{c}\boldsymbol{\Delta T} \\
\mathbf{K}\end{array}$ & $\begin{array}{c}\boldsymbol{T}_{\text {in }} \\
{ }^{\mathbf{}} \mathbf{C}\end{array}$ & $\begin{array}{c}\boldsymbol{T}_{\text {out }} \\
{ }^{\mathbf{o}} \mathbf{C}\end{array}$ & $\begin{array}{c}\boldsymbol{T}_{\text {in }}{ }^{*} \\
{ }^{\mathbf{}} \mathbf{C}\end{array}$ & $\begin{array}{c}\boldsymbol{T}_{\text {out }}{ }^{*} \\
{ }^{\mathbf{o}} \mathbf{C}\end{array}$ \\
\hline $\mathrm{DHW}$ & $j q d$ & Water & $5.9524 \cdot 10^{-3}$ & 4.200 & 0 & 40 & 20 & 60 & 20 & 60 \\
\hline $\mathrm{AS}$ & $j a s$ & Water & $12.4984 \cdot 10^{-3}$ & 4.200 & 0 & 30 & 60 & 90 & 60 & 90 \\
\hline $\mathrm{AD}$ & $j a d$ & Steam & $0.2964 \cdot 10^{-3}$ & 4.200 & 2015 & 90 & 90 & 180 & 90 & 180 \\
\hline VAP & $j v d$ & Steam & $0.4037 \cdot 10^{-3}$ & 4.200 & 2015 & 110 & 70 & 180 & 70 & 180 \\
\hline
\end{tabular}

A detailed representation of the thermal integration subsystem is shown in Figure 10, indicating the hot and cold flows associated with each technology and/or energy demand, as well as their names and their initial (supply) and final (target) temperatures; a total of 9 temperature intervals were identified, the first being the hottest. Temperature interval $k=3$ corresponds to the phase change from saturated water to saturated steam at $180{ }^{\circ} \mathrm{C}$, in which the hot flow igv provides latent heat $l h o$ and the cold flows jad and jvd consume latent heat $l h d$.

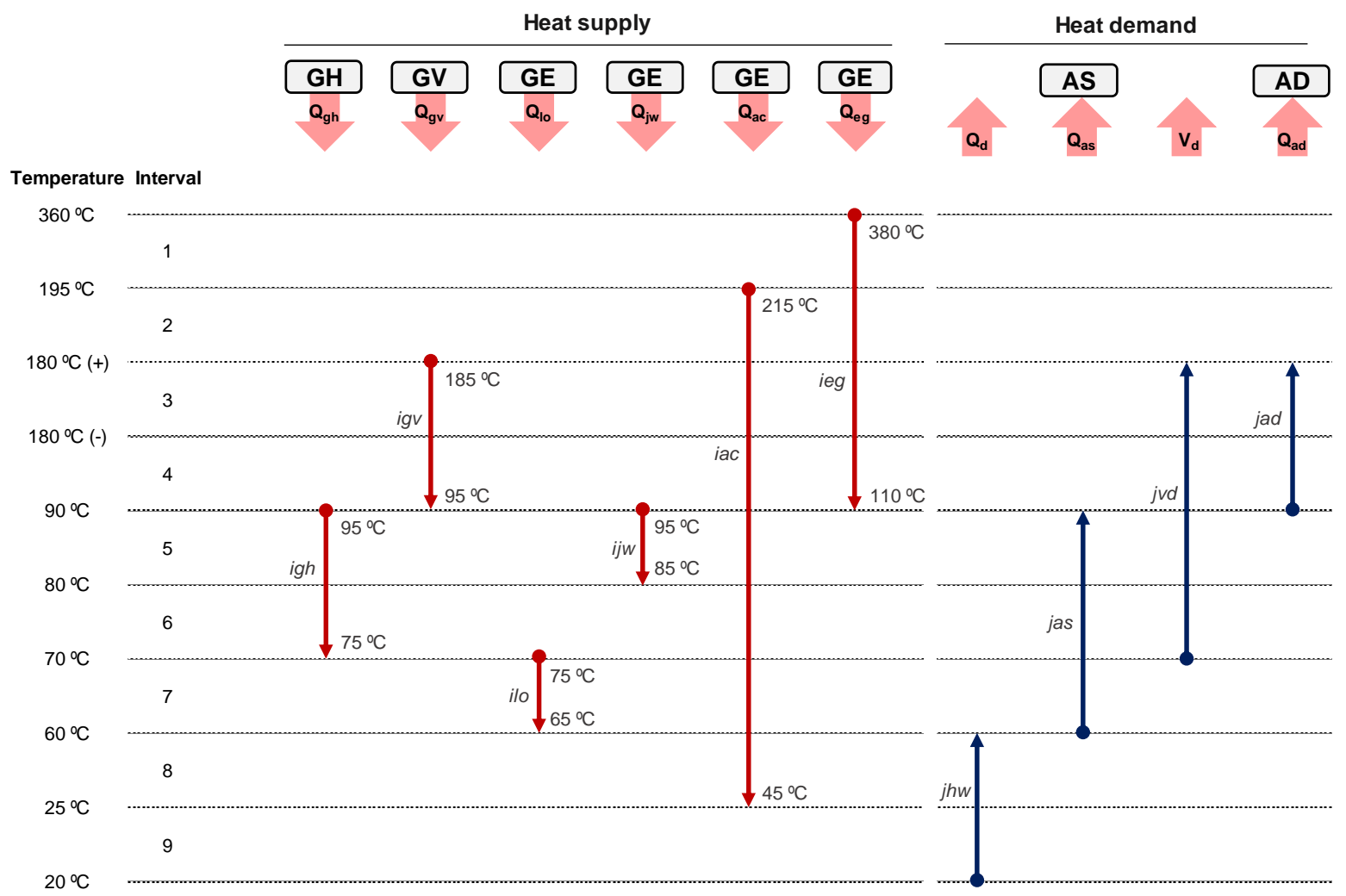

Figure 10: Thermal integration subsystem.

\subsection{Mathematical model}

A MILP model was developed to determine the optimal system configuration and operational strategy for the analyzed case study. The optimization model is composed of decision variables representing: (i) the existence and size of the technologies; (ii) the operation load of each technology in each time period; (iii) the energy resources exchanged with the market, i.e. 
electricity and natural gas; (iv) the heat supply and demand in each temperature interval; and (vi) the heat surplus from one temperature interval to the next (heat cascade). The existence of technologies and external (legal) restrictions, such as the permission to sell electricity to the grid, are represented by binary variables, while all other variables are continuous. Also, the time period set $\theta$, initially defined in Section 2 , is now expressed as $(d, h)$, representing the representative day $d$ and the hourly period $h$.

\subsubsection{Objective functions}

The objective function is the total annual cost $C T E_{t o t}$, which consists of the annual fixed cost $C T E_{f i x}$ and the annual variable cost $C T E_{v a r}$, calculated as

$C T E_{\text {tot }}=C T E_{\text {fix }}+C T E_{\text {var }}$

The annual fixed cost $C T E_{f i x}$ is given by Eq. (17), where $P I N(t)$ is the installed capacity of technology $t$.

$C T E_{f i x}=f a m \cdot\left(1+f_{I C}\right) \cdot \sum_{t} C I(t) \cdot \operatorname{PIN}(t)$

As previously mentioned, the operation of the system is described by 24 representative days $(N R D=24)$, each one composed of 24 consecutive periods $(N P=24)$ of 1 -hour duration $(N H P$ $=1)$. The annual variable cost $C T E_{v a r}$ corresponds to the sum, for each hourly period $h$ of each representative day $d$, of the costs of purchasing natural gas and electricity:

$$
\begin{aligned}
C T E_{\text {var }}= & \sum_{d}^{N R D} \sum_{h}^{N P} N R Y(d) \cdot N H P(h) \\
& \cdot\left(p_{\text {gas }} \cdot F_{p}(d, h)+p_{e p}(d, h) \cdot E_{p}(d, h)-p_{e s}(d, h) \cdot E_{s}(d, h)\right)
\end{aligned}
$$

\subsubsection{System constraints}

The objective function is subject to the following types of constraints:

(i) Installed capacity limits

For each technology $t$, the installed capacity $\operatorname{PIN}(t)$ is limited to the maximum installable capacity $\operatorname{PIN}_{M A X}(t)$, given in Table 8 , as expressed by Eq. (19). The binary variable $y I N S(t)$ expresses the permission to install or not the technology $t$.

$P I N(t) \leq \mathrm{yINS}(t) \cdot \operatorname{PIN} N_{M A X}(t)$

\section{(ii) Production restrictions}

Production restrictions involve inequality and equality constraints. The production of generation and transformation technologies $t$ is limited to its installed capacity $\operatorname{PIN}(t)$. An example is provided for the natural gas hot water boiler $\mathrm{GH}$ :

$Q_{g h}(d, h) \leq P I N(G H)$ 
Equality production restrictions relate the technology's energy consumption to its production. The auxiliary electricity consumption is calculated by multiplying the production by the unit auxiliary electricity consumption $C U e$. Examples of both restrictions are given below for the GH.

$Q_{g h}(d, h)-\eta_{g h} \cdot F_{g h}(d, h)=0$

$W_{\text {aux }, g h}(d, h)=C U e(G H) \cdot Q_{g h}(d, h)$

In the case of the cooling tower CT, the dissipated heat $Q_{d i s, c t}(d, h)$ is limited to the installed capacity $P I N(C T)$ according to Eq. (23). The CT dissipates heat from the transformation technologies $\left(Q_{d i s, a s}, Q_{d i s, a d}\right.$ and $\left.Q_{d i s, e c}\right)$ and from the thermal integration subsystem $Q_{d i s, i n t}$ as expressed by Eq. (24). The heat dissipated from the AS, AD and EC are obtained from Eqs. (25)-(27), respectively, and the heat dissipated from the thermal integration subsystem is expressed by Eq. (11).

$$
\begin{aligned}
& Q_{d i s, c t}(d, h) \leq P I N(C T) \\
& Q_{d i s, c t}(d, h)=Q_{d i s, a s}(d, h)+Q_{d i s, a d}(d, h)+Q_{d i s, e c}(d, h)+Q_{d i s, i n t}(d, h) \\
& Q_{d i s, a s}(d, h)=R_{a s}(d, h) \cdot(1+C U e(A S))+Q_{a s}(d, h) \\
& Q_{d i s, a d}(d, h)=R_{a d}(d, h) \cdot(1+C U e(A D))+Q_{a d}(d, h) \\
& Q_{d i s, e c}(d, h)=R_{e c}(d, h) \cdot\left(1+1 / C O P_{e c}\right)
\end{aligned}
$$

\section{(ii) Energy balances}

Equations (28)-(31) express the natural gas, cooling, electricity, and auxiliary electricity balances in each time period, respectively.

$$
\begin{aligned}
& F_{p}(d, h)-F_{g e}(d, h)-F_{g h}(d, h)-F_{g v}(d, h)=0 \\
& R_{e c}(d, h)+R_{a s}(d, h)+R_{a d}(d, h)-R_{d}(d, h)=0 \\
& E_{p}(d, h)+W_{g e}(d, h)-E_{d}(d, h)-E_{s}(d, h)-W_{e c}(d, h)-W_{a u x}(d, h)=0 \\
& W_{a u x}(d, h)-W_{a u x, g h}(d, h)-W_{a u x, g v}(d, h)-W_{a u x, a s}(d, h)-W_{a u x, a d}(d, h) \\
& \quad-W_{a u x, c t}(d, h)=0
\end{aligned}
$$

\section{(iii) Electric grid constraints}

The sold $E_{s}(d, h)$ and purchased $E_{p}(d, h)$ electricity are limited according to Eqs. (32) and (33), in which the binary variables $y E s$ and $y E p$ indicate the permission to sell electricity to the grid and the permission to purchase electricity from the grid, respectively.

$$
\begin{aligned}
& E_{s}(d, h) \leq y E s \cdot W_{g e}(d, h) \\
& E_{p}(d, h) \leq y E p \cdot\left(E_{d}(d, h)+W_{e c}(d, h)+W_{a u x}(d, h)\right)
\end{aligned}
$$

\section{(iv) Local policies constraints}

The Normative Resolution No. 235/2006 [58] issued by the Brazilian Electricity Regulatory Agency (ANEEL) defines the requirements for the qualification of cogeneration facilities in Brazil, which consist of a minimum annual equivalent electric efficiency $E E E_{Y}$ and a minimum 
annual heat efficiency $\eta_{q, Y}$. The Resolution provides Eq. (34) for the calculation of the $E E E_{Y}$, with the lower limit of $41 \%$ and the parameter 2.14 being defined according to the installed capacity and fuel consumed [58]. For the present study, the $\eta_{q, Y}$ is calculated from Eq. (35) and, in accordance with the Resolution, must be greater than or equal to $15 \%$. The annual electric efficiency $\eta_{w, Y}$ is expressed by Eq. (36). The subscript $Y$ denote annual values.

$$
\begin{aligned}
& E E E_{Y}=\eta_{w, Y}+\eta_{q, Y} / 2.14 \geq 41 \% \\
& \eta_{q, Y}=\left(Q_{g e, Y}-Q_{d i s, i n t, Y}\right) / F_{g e, Y} \geq 15 \% \\
& \eta_{w, Y}=W_{g e, Y} / F_{g e, Y}
\end{aligned}
$$

\section{(v) Thermal integration constraints}

The thermal integration constraints follow the mathematical implementation of the OPT described in Section 2. Two examples are provided to illustrate the modelling. For the hot flow igv associated with the natural gas steam boiler GV, Eqs. (5)-(7) and (14) can be expressed as follows.

$$
\begin{aligned}
& Q O(i g v, d, h)=\sum_{k} Q I K(i g v, k, d, h) \\
& Q I K(i g v, k, d, h)=\operatorname{mo}(i g v, d, h) \cdot \Delta h o(i g v, k) \\
& \Delta h o(i g v, k)=\operatorname{lho}(i g v, k), k=3 \\
& \Delta h o(i g v, k)=\operatorname{cpo}(i g v, k) \cdot \Delta T(k), k=4 \\
& m o(i g v, d, h)=\operatorname{mou}(i g v) \cdot Q_{g v}(d, h)
\end{aligned}
$$

It should be noted that a distinction was made in Eqs. (39) and (40) for the temperature intervals in which the GV supplies latent heat $(k=3)$ and sensible heat $(k=4)$. In Eq. (41), OPECAP $(\theta)$ corresponds to the device's main product, i.e. $Q_{g v}(d, h)$.

For the cold flow jas associated with the single-effect absorption chiller AS, Eqs. (8)-(10) and (14) can be expressed as follows.

$$
\begin{aligned}
& Q D(j a s, d, h)=\sum_{k} Q J K(j a s, k, d, h) \\
& Q J K(j a s, k, d, h)=m d(j a s, d, h) \cdot \Delta h d(j a s, k) \\
& \Delta h d(j a s, k)=c p d(j a s, k) \cdot \Delta T(k) \\
& m d(j a s, d, h)=m d u(j a s) \cdot R_{a s}(d, h)
\end{aligned}
$$

In Eq. (44) the latent heat term was omitted since the cold flow jas has no requirement for it. In Eq. (45), $O P E C A P(\theta)$ corresponds to the device's main product, i.e. $R_{a s}(d, h)$.

\subsection{Economic optimal configurations}

The MILP model was implemented and solved using the software LINGO [59]. Three different energy supply systems were assessed using the binary variable $y I N S(t)$ to impose specific system configurations, as explained in Table 11. The optimal economic cost solutions are 
shown in Table 12, in which $Z(t)$ is the investment cost of the technology, obtained by multiplying its installed capacity $\operatorname{PIN}(t)$ by its bare module cost $C I(t)$.

Table 11: Analyzed system configurations.

\begin{tabular}{|c|c|}
\hline System & Description \\
\hline Reference system & $\begin{array}{c}\text { Conventional separate production of energy services } \\
\text { - } y I N S(t)=1 \text {, for } t=\mathrm{GH}, \mathrm{GV}, \mathrm{EC} \text {, and } \mathrm{CT} \\
\text { - } y I N S(t)=0 \text {, for the remaining technologies }\end{array}$ \\
\hline CHP system & $\begin{array}{l}\text { Combined production of heat and power } \\
\text { - } y I N S(t)=1 \text {, for } t=\mathrm{GE}, \mathrm{GH}, \mathrm{GV}, \mathrm{EC} \text {, and } \mathrm{CT} \\
\text { - } y I N S(t)=0 \text {, for the remaining technologies }\end{array}$ \\
\hline CCHP system & $\begin{array}{l}\text { Combined production of cooling, heat and power } \\
\text { - } \quad y I N S(t)=1 \text {, for all candidate technologies }\end{array}$ \\
\hline
\end{tabular}

Table 12: Optimal cost solutions.

\begin{tabular}{|c|c|c|c|c|c|c|c|c|c|}
\hline \multirow[b]{2}{*}{ Results } & \multicolumn{3}{|c|}{ Reference system } & \multicolumn{3}{|c|}{ CHP system } & \multicolumn{3}{|c|}{ CCHP system } \\
\hline & $\begin{array}{c}P I N(t), \\
\text { kW }\end{array}$ & $\begin{array}{l}\text { Load } \\
\text { factor }\end{array}$ & $\begin{array}{c}Z(t), \\
\mathbf{k} €\end{array}$ & $\begin{array}{c}P I N(t), \\
\text { kW }\end{array}$ & $\begin{array}{l}\text { Load } \\
\text { factor }\end{array}$ & $\begin{array}{c}Z(t), \\
\mathbf{k} €\end{array}$ & $\begin{array}{c}P I N(t), \\
\text { kW }\end{array}$ & $\begin{array}{l}\text { Load } \\
\text { factor }\end{array}$ & $\begin{array}{c}Z(t), \\
\mathbf{k} €\end{array}$ \\
\hline GE Cogeneration module & - & - & - & 1,545 & $99.8 \%$ & $1,043.0$ & 1,591 & $99.8 \%$ & $1,073.9$ \\
\hline GV Steam boiler & 780 & $75.6 \%$ & 93.6 & 158 & $7.9 \%$ & 18.9 & 141 & $6.3 \%$ & 16.9 \\
\hline GH Hot water boiler & 76 & $1.6 \%$ & 4.2 & 0 & - & 0 & 0 & - & 0 \\
\hline $\begin{array}{l}\text { AS Single-effect } \\
\text { absorption chiller }\end{array}$ & - & - & - & - & - & - & 489 & $91.1 \%$ & 127.2 \\
\hline $\begin{array}{l}\text { AD Double-effect } \\
\text { absorption chiller }\end{array}$ & - & - & - & - & - & - & 26 & $48.7 \%$ & 6.8 \\
\hline EC Mechanical chiller & 879 & $61.7 \%$ & 92.3 & 879 & $61.7 \%$ & 92.3 & 365 & $23.2 \%$ & 38.4 \\
\hline CT Cooling tower & 1,023 & $61.7 \%$ & 30.7 & 1,791 & $85.3 \%$ & 53.7 & 1,753 & $85.3 \%$ & 52.6 \\
\hline Natural gas, MWh/yr & \multicolumn{3}{|r|}{5,567} & \multicolumn{3}{|r|}{29,026} & \multicolumn{3}{|r|}{29,851} \\
\hline $\begin{array}{l}\text { Purchased electricity, } \\
\mathrm{MWh} / \mathrm{yr}\end{array}$ & \multicolumn{3}{|c|}{10,466} & \multicolumn{3}{|r|}{249} & \multicolumn{3}{|r|}{103} \\
\hline Sold electricity, $\mathrm{MWh} / \mathrm{yr}$ & \multicolumn{3}{|r|}{-} & \multicolumn{3}{|r|}{2,878} & \multicolumn{3}{|r|}{3,760} \\
\hline $\begin{array}{l}\text { Dissipated cogenerated } \\
\text { heat, } \mathrm{MWh} / \mathrm{yr}\end{array}$ & \multicolumn{3}{|r|}{-} & \multicolumn{3}{|r|}{7,846} & \multicolumn{3}{|r|}{1,975} \\
\hline Natural gas, $€ /$ yr & \multicolumn{3}{|c|}{194,851} & \multicolumn{3}{|r|}{$1,015,911$} & \multicolumn{3}{|r|}{$1,044,792$} \\
\hline Purchased electricity, $€ / \mathrm{yr}$ & \multicolumn{3}{|c|}{$1,021,641$} & \multicolumn{3}{|r|}{23,411} & \multicolumn{3}{|r|}{9,709} \\
\hline Sold electricity, $€ / \mathrm{yr}$ & \multicolumn{3}{|r|}{-} & \multicolumn{3}{|r|}{245,269} & \multicolumn{3}{|r|}{321,365} \\
\hline Annual fixed cost, $€ / y r$ & \multicolumn{3}{|c|}{39,753} & \multicolumn{3}{|r|}{217,429} & \multicolumn{3}{|r|}{236,829} \\
\hline Annual operation cost, $€ / y r$ & \multicolumn{3}{|c|}{$1,216,492$} & \multicolumn{3}{|r|}{794,053} & \multicolumn{3}{|r|}{733,136} \\
\hline Total annual cost, $€ / y r$ & \multicolumn{3}{|c|}{$1,256,245$} & \multicolumn{3}{|r|}{$1,011,482$} & & & 969,964 \\
\hline Total investment cost, $€$ & & & 0,847 & & & $1,207,937$ & & & $1,315,716$ \\
\hline Payback period, yr & & & - & & & 2.3 & & & 2.2 \\
\hline $\begin{array}{l}\text { GE annual equivalent } \\
\text { electric efficiency } E E E_{Y}\end{array}$ & & & - & & & $54.9 \%$ & & & $64.5 \%$ \\
\hline $\begin{array}{l}\text { GE annual heat efficiency } \\
\eta_{q, Y}\end{array}$ & & & - & & & $17.5 \%$ & & & $38.0 \%$ \\
\hline
\end{tabular}

In the case of the reference system, the electricity demand, as well as the internally consumed electricity, were entirely covered by purchase from the electric grid; the steam and hot water 
demands were predominantly supplied by the natural gas steam boiler GV, while the natural gas hot water boiler GH operated only in a few peak hours; and the cooling demand was attended by the mechanical chiller EC. The cooling tower CT was installed with the sole purpose of dissipating the heat from the EC. The total annual cost obtained for the reference system was equal to $1,256,245 € / \mathrm{yr}$, of which $96.8 \%$ corresponded to operation (variable) costs and the remaining 3.2\% corresponded to installation (fixed) costs. Electricity purchase accounted for the largest share $(84.0 \%)$ of the annual operation cost. Regarding the annual fixed cost, the largest shares were attributable to the GV (42.4\%) and EC (41.8\%), respectively.

The optimal cost solution for the CHP system included all the allowed technologies except for the GH. The cogeneration module GE operated with a very high load factor (99.8\%), which allowed the system to sell $21 \%$ of the electricity produced, generating substantial revenue to partially compensate the operation costs, and almost eliminating the need for electricity purchase. The GE heat production led to a significant reduction in the installed capacity and operation of the GV and removed the GH. On the other hand, the increased operation of the GE also resulted in a higher dissipation of cogenerated heat, which reached $60.7 \%$ of the cogenerated heat produced, and a low GE heat efficiency of $\eta_{q, Y}=17.5 \%$, close to the minimum legal requirement of $15 \%$ (Eq. (35)). The GE annual equivalent electric efficiency $E E E_{Y}$ was $54.9 \%$, considerably higher than the minimum legal requirement of $41 \%$ (Eq. (34)); nevertheless, because the GE electric efficiency is always a constant $46.7 \%$ (Table 8), this restriction is never active and the $E E E_{Y}$ will vary according to the GE annual heat efficiency. Since absorption chillers were not allowed to be installed in this configuration, cooling was entirely covered by the EC with electricity produced by the system and purchased from the grid. The optimal cost solution resulted in a total annual cost of $1,011,482 € / \mathrm{yr}$, of which $78.5 \%$ corresponded to operation costs and $21.5 \%$ corresponded to fixed costs. Regarding the annual fixed cost, the GE accounted for the largest share, $86.3 \%$.

By further improving the system's deployment of cogenerated heat, the optimal cost solution for the CCHP system included all the allowed technologies except for the GH. Relative to the CHP system, the installed capacities of the GE and CT remained about the same, while the EC and GV were reduced by $58.5 \%$ and $10.8 \%$, respectively. In the light of the installation of both single- and double-effect absorption chillers, the GE operated with the same load factor as that of the CHP system, but with a considerably higher heat utilization; in fact, dissipation of cogenerated heat fell from $60.7 \%$ in the CHP system to $14.9 \%$, and the resulting $\eta_{q, Y}$ and $E E E_{Y}$ increased from $17.5 \%$ to $38.0 \%$ and from $54.9 \%$ to $64.5 \%$, respectively. Moreover, EC electricity consumption decreased accordingly, which allowed more electricity to be sold to the grid, generating more revenue. For this system, a total annual cost of $969,964 € / y r$ was obtained, of which $75.6 \%$ corresponded to operation costs and $24.4 \%$ corresponded to fixed costs. Again, the GE accounted for the largest share of the annual fixed cost $(81.6 \%)$, followed by the singleeffect absorption chiller AS (9.7\%).

Compared with the reference system, the more complex configurations $\mathrm{CHP}$ and CCHP require higher investment costs, which are compensated by savings in the consumption of energy resources during the operation of the plant. This was observed in the previous discussion about the different compositions of the total annual cost, in which the share of annual fixed cost 
increased while the share of annual operation cost decreased. Taking, for example, the optimal cost solution for the CHP system, the ratio of the increased investment cost $(1,207,937$ $220,847=987,090 €)$ to the annual savings in operation costs $(1,216,492-794,053=422,439$ $€ / y r)$ results in a payback period of 2.3 years, which is the period of time required to recoup the invested funds. In the case of the CCHP system its payback period is slightly lower (2.2 years), indicating the greater benefits that can be achieved by the CCHP system relative to the CHP system, such as the production of an additional energy service (i.e. cooling) and the higher heat efficiency, despite the higher investment costs required.

As can be seen, the GE was proved economically feasible to supply the hospital's energy demands, operating with very high load factors. Relative to the reference system, the presence of the GE in the CHP and CCHP systems: (i) eliminated the natural gas hot water boiler GH; (ii) drastically reduced the installed capacity of GV; and (iii) enabled the installation of the single-effect AS and, to a lesser extent, the double-effect AD absorption chillers. In fact, the $\mathrm{AS}$ and $\mathrm{AD}$ were proven feasible options for cooling production as long as they were coupled to the cogeneration module.

In order to understand the role of the GE in the optimal operation of the system, it is important to consider its several heat sources at different temperature levels and their relationship with the hospital's thermal energy demands. The hospital has a greater demand for high-temperature heat (i.e. saturated steam) than for low-temperature heat (i.e. hot water). In accordance with the explanation provided in Section 3, the operation of the GE for steam production results in the simultaneous production of excess low-temperature heat, which is optimally used in the AS. Therefore, there is a clear connection between the GE and the AS, which justifies the installation of the AS, instead of the $\mathrm{AD}$, despite its lower COP.

\subsection{Optimal operation of the CCHP system}

Owing to the fact that the CCHP system is technically and economically more advantageous than the CHP system to cover the hospital's energy demands, this configuration was selected for more detailed analysis regarding its optimal operation. Apart from the installed capacities and the main results discussed in Section 4.4, the optimization model also obtains the system's annual and hourly energy operating strategies. The annual energy flows are illustrated in Figure 11 (in plain text), complementing the information shown in Table 12. Concerning the hourly operation of the system, Figure 12 shows the hourly energy flows of a working day in January and Figure 11 depicts the operation of the system at hour 16 of that day (in italics). 


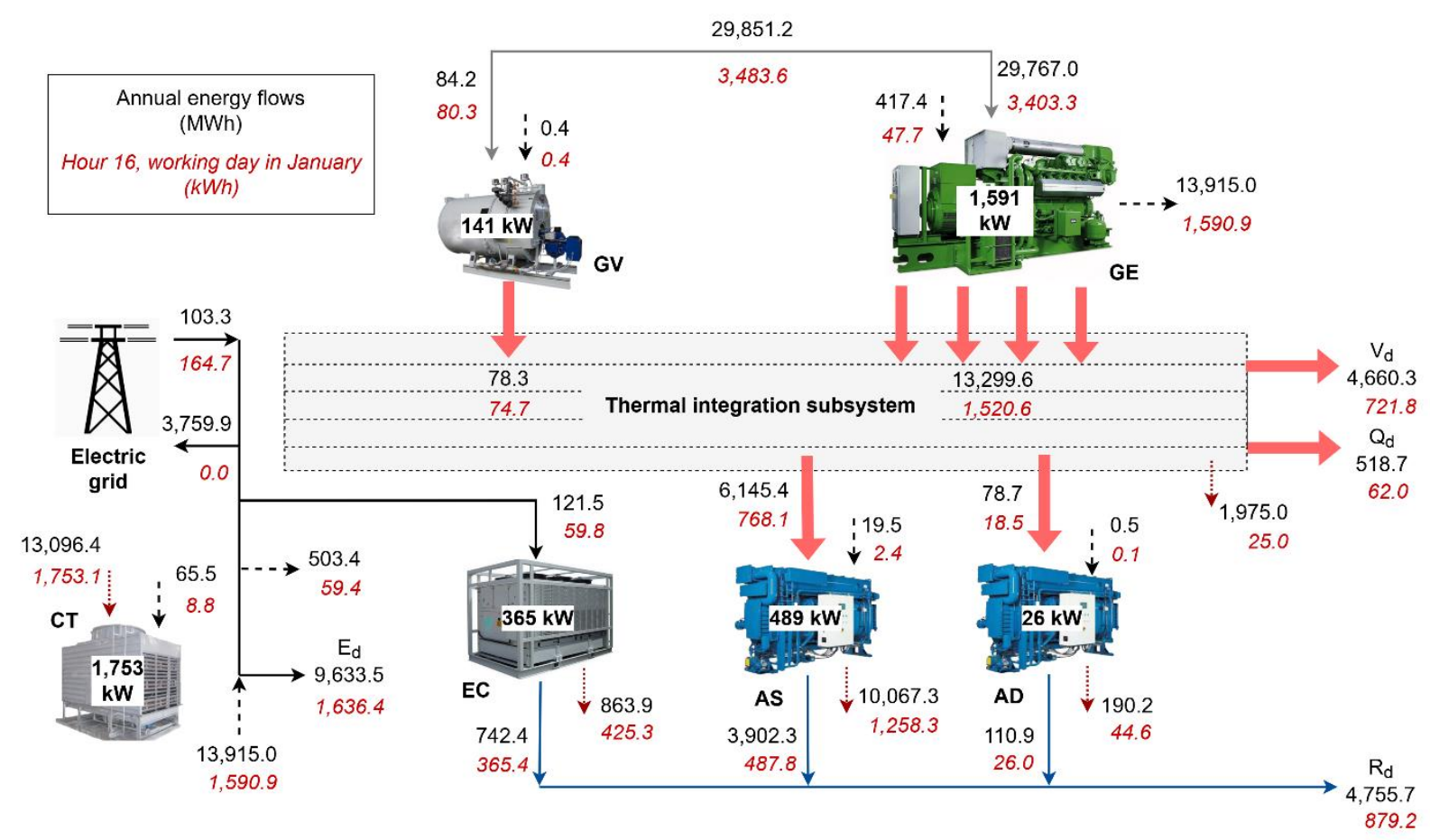

Figure 11: Annual energy flows (plain text) and hourly operation of a working day in January, hour 16 (in italics).
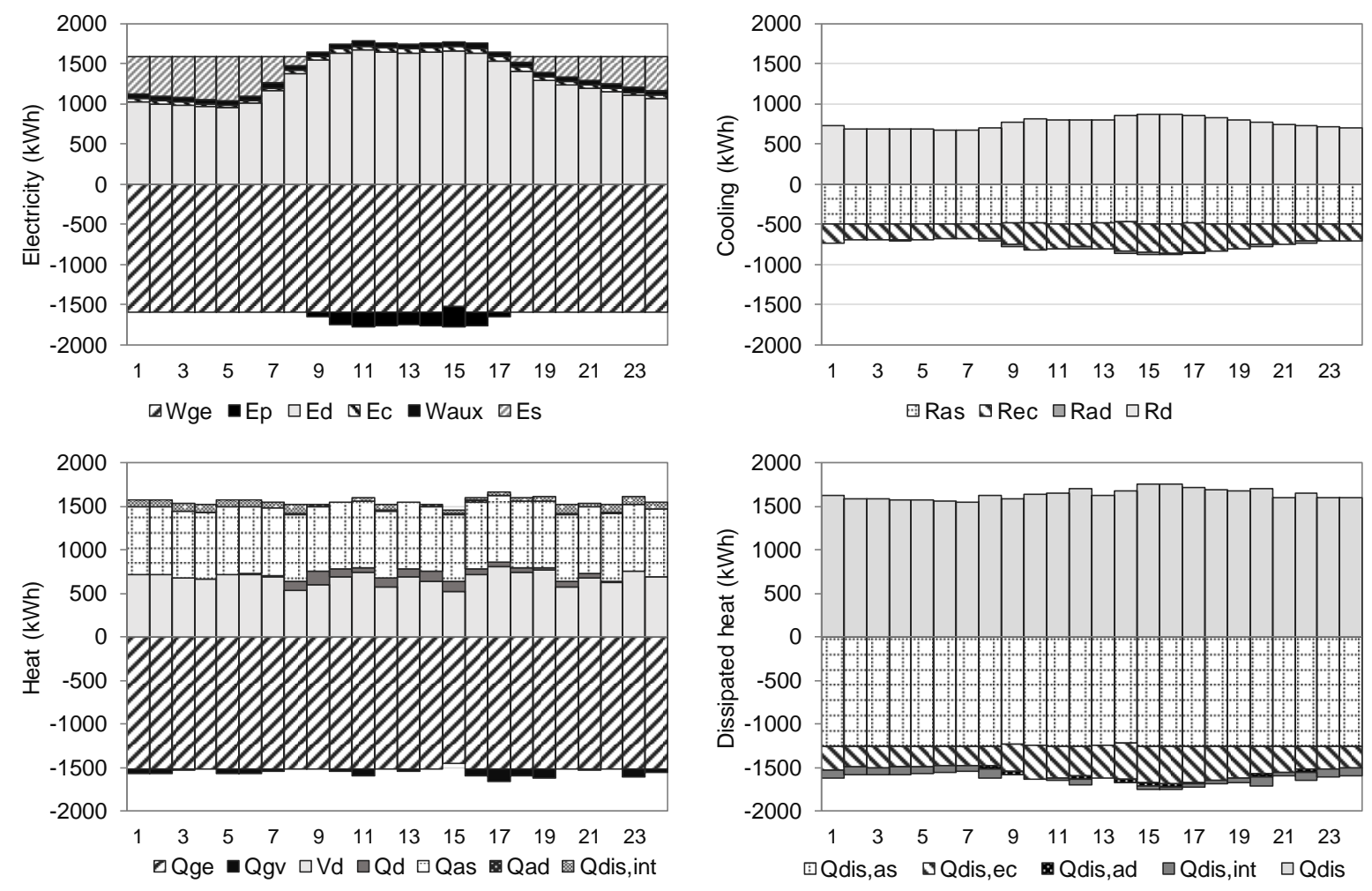

Figure 12: Hourly energy flows of a working day in January.

Starting with the annual operation of the CCHP system, Figure 11 shows that the GE is the main source of electricity and heat, while the electric grid and the GV only cover peak demands. 
The electricity consumption consists of electricity demand $E_{d}(93.9 \%)$, auxiliary electricity $(4.9 \%)$ and EC (1.2\%). Virtually all of this consumption is supplied by the GE, about $99.0 \%$. Besides, $27.0 \%$ of the electricity produced by the GE is sold to the electric grid. The GE is also responsible for $99.4 \%$ of the heat produced by the system. Concerning the way in which the produced heat is used, the AS accounts for the largest share of about $45.9 \%$, followed by the steam demand $V_{d}$ with $34.8 \%$. About $14.8 \%(1,975.0 \mathrm{MWh})$ of the heat produced must be dissipated. It can be safely assumed that all the dissipated heat is produced by the GE, since it makes no economic sense to dissipate heat from the GV. Regarding cooling production, the main technology is the AS, responsible for $82.1 \%$ of the annual supply, supported by the EC and, to a lesser extent, the AD. Heat dissipation in the CT is mostly due to the AS with $76.9 \%$ and the cogenerated heat dissipation with $15.1 \%$.

The working day in January provides an interesting scenario for further analysis as it contains the peak demands of electricity $1671.7 \mathrm{kWh}$, cooling $879.2 \mathrm{kWh}$, and steam $807.7 \mathrm{kWh}$, which put the system under considerable stress and promote greater synergies between the technologies. The hourly profiles of electricity, heat, cooling, and dissipated heat are depicted in Figure 12. The system operation generally follows in the footsteps of the annual energy flows previously described. It is noted that the GE operates at full load throughout the day except for hour 15, when its operating capacity is slightly reduced, incurring in higher electricity purchase from the grid. This can be explained by the fact that the operation of thermal-driven technologies is also constrained by the system's capacity to evacuate heat in the cooling tower. At hour 15, the CT is operating at its maximum capacity; operating the GE at full load is a more costly alternative to purchasing electricity from the grid as it would result in more heat dissipation which, in turn, would require a higher installed capacity of CT and, thus, higher investment costs.

It is also worth examining the operation of the system at hour 16, when cooling demand peaks and steam demand is very high. As can be seen in Figure 11 (in italics), all devices are operating at full load, except for the GV, and the system is purchasing electricity. About $9.4 \%$ of the electricity consumed by the system is supplied by the grid. Cooling production is distributed between the AS (55.5\%) and the EC (41.6\%). In the case of the produced heat, it is mostly used to drive the AS (48.1\%) and to cover the steam demand $V_{d}(45.2 \%)$; only a small share of $1.6 \%$ must be dissipated. Almost all of the heat dissipated in the CT is due to cooling production in the AS and EC, with $71.8 \%$ and $24.3 \%$, respectively. Let us take a look at the heat exchange that is taking place in the thermal integration subsystem, shown in detail in Figure 13. 


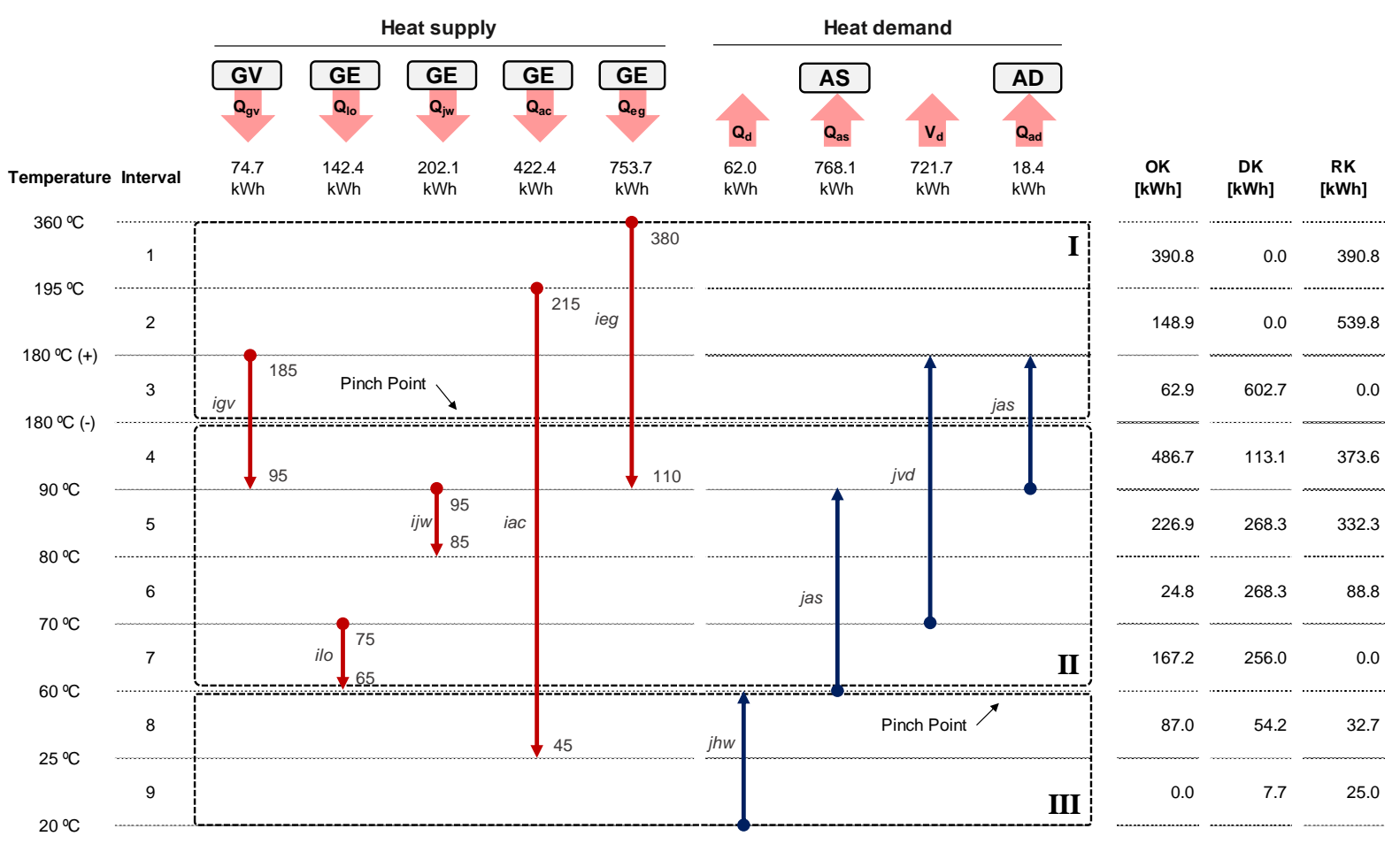

Figure 13: Thermal integration subsystem of a working day in January, hour 16.

The GE and GV supply hot flows, providing the heat required by the cold flows associated with the hot water $Q_{d}$ and steam $V_{d}$ demands, and the absorption chillers AS, $Q_{a s}$, and AD, $Q_{a d}$. It is possible to divide the temperature intervals into three regions in which the heat supplied by the hot flows $O K$ is entirely consumed by the corresponding cold flows $D K$. The limits between these regions indicate the existence of a pinch point at $180^{\circ} \mathrm{C}$, between temperature intervals 3 and 4 , and at $60^{\circ} \mathrm{C}$, between temperature intervals 7 and 8 . As can be seen, in the top region (I), the high-temperature heat flows supplied by the GE ( $Q_{e g}$ and $\left.Q_{a c}\right)$ and GV $\left(Q_{g v}\right)$ cover the greatest part of steam production $V_{d}$ and $Q_{a d}$, while in the middle (II) and lower (III) regions the remaining cold flows are attended. It is interesting to note that the hot water $Q_{d}$ is entirely covered by the charge air in region III. Besides, in this hour there is heat dissipation of $25 \mathrm{kWh}$, specifically from the charge air iac.

It is evident by now that the synthesis is a complex problem that tackles a great number of variables (plant and user characteristics, building types, climatic conditions, system configurations, operating strategies, regulatory and economic aspects, among others), which renders the optimal solution unique to the problem at hand and to the set of conditions and assumptions considered. It has been amply demonstrated that the feasibility of energy supply systems is strongly influenced by these parameters; for instance, in the case of CCHP systems for different building types and across various climate zones in Japan [60] and the US [61]. Nevertheless, general observations can still be made.

The results presented thus far demonstrated the technical and economic feasibility of gas engine-based CHP and CCHP systems to cover the Brazilian hospital's energy demands, translated into low payback periods of about 2.3 years. These results agree with the body of research that verified the potential benefits that can be derived from CCHP system in hospital 
facilities, such as in Spain [14], Italy [62], and Brazil [63], to name a few examples. One of the key factors contributing to the aforementioned low payback periods was the considerable savings in operation cost attributed to electricity purchase reduction and to electricity sale revenue. The role of the electric grid in promoting cost savings has also been identified by Ahn et al. [64] for CCHP systems in large office buildings across the US. In addition, the results suggested the interest of cooling production in single-effect absorption chillers, and to a lesser extent in double-effect absorption chillers, as long as they were driven by cogenerated heat. This is in agreement with the findings by Ahn et al. [65] about a hybrid electric-absorption chiller in a gas engine-based CCHP system.

\subsection{Sensitivity analysis}

Sensitivity analysis is performed herein for key factors influencing the optimal CCHP system discussed in the previous sections, including the natural gas and electricity purchase prices, the penalization of the electricity selling price, the amortization and maintenance factor, and the Brazilian requirement for minimum GE annual heat efficiency. Moreover, the effect of removing the permission to sell electricity to the grid is analyzed. The primary focus will be on the CCHP system on account of it being the preferable solution.

The effect of the variation of natural gas price $p_{\text {gas }}$ on the optimal CCHP system is shown in Table 13 and Figure 14; the hot water boiler GH was omitted from the table because it was not included in any solution. The results show that a rise of $p_{\text {gas }}$ hinders the implementation of cogeneration, leading to higher total annual costs. It is noted that when the installed capacity of GE decreases, so do the AS, AD and CT, while the GV and EC increase, resulting in lower annual fixed costs. Since there is less cogeneration, the system produces less electricity, which seriously compromises the revenue from electricity sale and increases purchase, thus leading to higher annual operation costs. The more expensive natural gas resource promotes a better use of the cogenerated heat, so that heat dissipation is greatly diminished, improving the GE annual heat efficiency. When the gas price increases by $20 \%$, the total annual cost increases by $18.8 \%$. The GV sees its capacity more than double, while the GE and CT are reduced by about $24.1 \%$ and $13.5 \%$, respectively; regarding cooling production, the AS decreases by $24.5 \%$, being replaced by the EC, which increases by $39.6 \%$, and the $\mathrm{AD}$ is no longer installed. As a result, the annual fixed cost is cut down by $20.5 \%$. On the other hand, a substantial increase in electricity purchase and decrease in electricity sale ensue, raising the annual operation cost by $31.5 \%$. 
Table 13: Sensitivity analysis for the natural gas purchase price.

\begin{tabular}{|c|c|c|c|c|c|c|c|}
\hline \multirow{3}{*}{$p_{\text {gas }}, € / \mathbf{k W h}(\mathrm{LHV})$} & \multicolumn{7}{|c|}{ CCHP system } \\
\hline & $-30 \%$ & $-20 \%$ & $-10 \%$ & $0 \%$ & $10 \%$ & $20 \%$ & $30 \%$ \\
\hline & 0.025 & 0.028 & 0.032 & 0.035 & 0.039 & 0.042 & 0.046 \\
\hline \multicolumn{8}{|l|}{$P I N(t), \mathrm{kW}$} \\
\hline GE Cogeneration module & 4,503 & 4,500 & 2,002 & 1,591 & 1,380 & 1,208 & 977 \\
\hline GV Steam boiler & 0 & 0 & 0 & 141 & 224 & 294 & 387 \\
\hline $\begin{array}{l}\text { AS Single-effect absorption } \\
\text { chiller }\end{array}$ & 821 & 804 & 616 & 489 & 423 & 369 & 295 \\
\hline $\begin{array}{l}\text { AD Double-effect } \\
\text { absorption chiller }\end{array}$ & 0 & 0 & 62 & 26 & 22 & 0 & 0 \\
\hline EC Mechanical chiller & 59 & 75 & 201 & 365 & 435 & 510 & 591 \\
\hline CT Cooling tower & 4,493 & 4,490 & 2,103 & 1,753 & 1,647 & 1,550 & 1,431 \\
\hline Natural gas, MWh/yr & $84,334.1$ & $84,268.7$ & $37,457.2$ & $29,851.2$ & $25,470.7$ & $22,980.4$ & $19,446.7$ \\
\hline $\begin{array}{l}\text { Purchased electricity, } \\
\mathrm{MWh} / \mathrm{yr}\end{array}$ & 0.0 & 0.0 & 0.0 & 103.3 & 398.4 & 870.9 & $2,053.9$ \\
\hline Sold electricity, MWh/yr & $28,395.0$ & $28,364.5$ & $7,217.9$ & $3,759.9$ & $1,898.4$ & $1,003.9$ & 206.1 \\
\hline $\begin{array}{l}\text { Dissipated cogenerated heat, } \\
\mathrm{MWh} / \mathrm{yr}\end{array}$ & $25,029.6$ & $25,010.2$ & $4,487.2$ & $1,975.0$ & 791.8 & 526.0 & 197.1 \\
\hline Natural gas, $\mathrm{k} € / \mathrm{yr}$ & $2,108.3$ & $2,359.5$ & $1,198.6$ & $1,044.8$ & 993.4 & 965.2 & 894.6 \\
\hline Purchased electricity, k€/yr & 0.0 & 0.0 & 0.0 & 9.7 & 37.5 & 82.9 & 199.6 \\
\hline Sold electricity, $\mathrm{k} € / \mathrm{yr}$ & $2,430.5$ & $2,427.9$ & 617.8 & 321.4 & 162.1 & 84.2 & 16.9 \\
\hline Annual fixed cost, $\mathrm{k} € / \mathrm{yr}$ & 610.9 & 610.0 & 290.1 & 236.8 & 210.5 & 188.3 & 159.7 \\
\hline Annual operation cost, $\mathrm{k} € / \mathrm{yr}$ & -322.1 & -68.3 & 580.8 & 733.1 & 868.8 & 963.9 & $1,077.3$ \\
\hline Total annual cost, $\mathrm{k} € / \mathrm{yr}$ & 288.8 & 541.7 & 871.0 & 970.0 & $1,079.3$ & $1,152.2$ & $1,237.0$ \\
\hline Total investment cost, $\mathrm{k} €$ & $4,072.7$ & $4,066.6$ & $1,934.3$ & $1,315.7$ & $1,403.4$ & $1,255.6$ & $1,064.7$ \\
\hline Payback period, yr & 2.5 & 3.0 & 2.7 & 2.2 & 3.4 & 4.1 & 6.1 \\
\hline $\begin{array}{l}\text { GE annual equivalent electric } \\
\text { efficiency } E E E_{Y}\end{array}$ & $53.8 \%$ & $53.8 \%$ & $62.0 \%$ & $64.5 \%$ & $66.2 \%$ & $66.5 \%$ & $67.1 \%$ \\
\hline GE annual heat efficiency $\eta_{q, Y}$ & $15.0 \%$ & $15.0 \%$ & $32.7 \%$ & $38.0 \%$ & $41.5 \%$ & $42.3 \%$ & $43.6 \%$ \\
\hline
\end{tabular}

Note: Italic indicates an active restriction. 


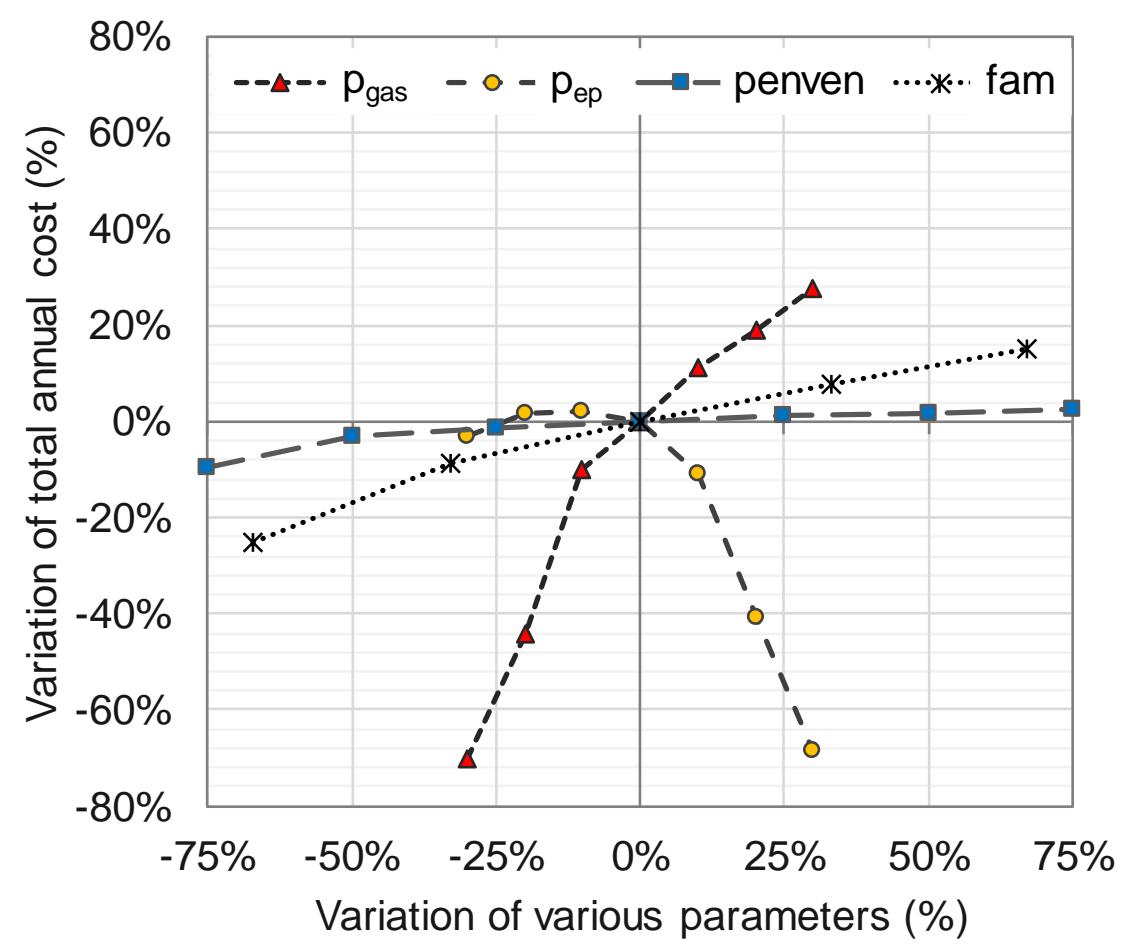

Figure 14: Influence of natural gas and electricity prices, penalization, and amortization and maintenance factor on the total annual cost of the CCHP system.

The opposite trend is observed for the decrease of $p_{\text {gas }}$ : the deployment of cogeneration is encouraged, promoting a reduction in the total annual cost. When the gas price reduces by $20 \%$, the total annual cost is cut down by $44.2 \%$. A remarkable increase in GE takes place, from $1,591 \mathrm{~kW}$ to $4,500 \mathrm{~kW}$, promoting the installation of AS (64.4\%) and CT (150.7\%), displacing the EC by $79.4 \%$, and eliminating the $\mathrm{GV}$ and $\mathrm{AD}$. This results in $157.6 \%$ higher annual fixed cost. The annual operation cost, on the other hand, is $109.3 \%$ lower, becoming negative as a result of a sharp increase in electricity sale. Besides, it is observed that the larger installed capacity of GE dramatically increases heat dissipation. Consequently, the GE annual heat efficiency of the system falls from $38.0 \%$ to $15.0 \%$, reaching the minimum legal requirement (Eq. (35)), which becomes an active constraint (the inequality constraint is at its limit). As a result, the further deployment of GE is hindered, as can be seen by the negligible increase in GE when the natural gas price is decreased from $20 \%$ to $30 \%$.

The synergy between the GE and AS highlighted in Sections 4.4 and 4.5 is made even clearer now, since the installed capacity of AS increases or decreases along with the GE, displacing or being displaced by the EC. Additionally, it is noteworthy that the AD is only installed in intermediate solutions close to the base case (within the variation range of about $\pm 10 \%$ in the gas price), being no longer included either when there is too much GE, which potentializes the benefits of the AS rendering the AD unnecessary, or when there is not enough of GE to drive the $\mathrm{AD}$ and to cover the hospital's steam demand.

Apart from the natural gas price $p_{\text {gas }}$, the effects of the variation of the electricity purchase price $p_{e p}$, the penalization of the electricity selling price penven, and the amortization and maintenance factor fam were also assessed. Their individual influences on the total annual cost 
of the CCHP system are illustrated in Figure 14. While their impacts are clearly different from each other, the results show that the effects of penven and fam generally follow the same reasoning as explained for the $p_{\text {gas }}$. By contrast, it is noted that either increasing or decreasing the $p_{e p}$ reduces the total annual cost. The effect of increasing $p_{e p}$ is similar to that of decreasing $p_{\text {gas }}$, that is, it encourages self-generation of electricity in the GE, which not only reduces the cost of electricity purchase but also increases the revenue from electricity sale. It is observed that when $p_{e p}$ increases by $10 \%$, the total annual cost reduces by $11.0 \%$, and the system reaches the minimum legal requirement of $15.0 \%$ (Eq. (35)). Regarding the reduction in $p_{e p}$, the result is that it compromises the economic viability of self-generated electricity in the GE, so there is a shift in the system from natural gas for cogeneration purposes to electricity purchase from the grid.

The penalization of the electricity selling price was the parameter with the least influence on the total annual cost. For the particular case study analyzed herein, this demonstrates that the economic feasibility of the GE is not dependent on electricity sale. This is made evident when the permission to sell electricity to the grid is denied $(y E s=0)$, as shown in Table 14. Compared to the CCHP system with electricity sale (Table 12), the GE remains the key device, with an installed capacity about $27.4 \%$ smaller. Even though the system can no longer generate revenue from selling electricity to the grid, the total annual cost increases only by $4.7 \%$, and the payback period rises from 2.2 to 2.6 years.

Piacentino et al. [66] assessed the influence of a fuel tax exemption for CHP and CCHP systems, identifying that while a moderate tax exemption improved their economic feasibility, an excessive reduction in the fuel cost enabled the operation of the system as a "power unit", whereby the system minimized costs by producing electricity to the detriment of a more rational use of the waste heat. A similar parallel can be drawn in here with the Brazilian requirement of a minimum GE annual heat efficiency $\eta_{q, Y}$. Despite the fact that this constraint was not active in the cost optimal CCHP solution, the sensitivity analysis indicates that it can easily do so (with $10 \%$ higher $p_{e p}$ or $20 \%$ lower $p_{g a s}$ ). The current value of $15 \%$ is sufficiently low to enable the system operation under such "power unit" mode, thus raising the question as to the energetic and environmental benefits of the combined production of energy services in such cases.

Increasing the minimum requirement of $\eta_{q, Y}$ would have a much more appreciable effect on the CHP system than on the CCHP system. This can be explained by the fact that the CCHP already presented a very high $\eta_{q, Y}$ of $38.0 \%$, close to the GE technical limit of $44.6 \%$ in which there is no dissipation of cogenerated heat, while the CHP presented a very low $\eta_{q, Y}$ of $17.5 \%$. In any case, it is noteworthy that the total annual cost increases with the minimum requirement of $\eta_{q, Y}$ as the system is required to change from a process integrated (cogeneration based) configuration to a more conventional one (gas boiler and mechanical chiller based). The variation of the installed capacities of key devices and annual costs with $\eta_{q, Y}$ are illustrated in Figure 15 for the CCHP system. 
Table 14: Effect of removing the permission to sell electricity.

\begin{tabular}{|c|c|c|c|}
\hline \multirow[b]{2}{*}{ Results } & \multicolumn{3}{|c|}{ CCHP system } \\
\hline & $\begin{array}{c}P I N(t), \\
\text { kW }\end{array}$ & Load factor & $\begin{array}{c}Z(t), \\
\mathbf{k} €\end{array}$ \\
\hline GE Cogeneration module & 1,155 & $91.4 \%$ & 935.5 \\
\hline GV Steam boiler & 316 & $38.6 \%$ & 45.5 \\
\hline GH Hot water boiler & 0 & - & 0 \\
\hline AS Single-effect absorption chiller & 350 & $90.2 \%$ & 109.1 \\
\hline AD Double-effect absorption chiller & 0 & $\%$ & 0 \\
\hline EC Mechanical chiller & 529 & $43.0 \%$ & 66.7 \\
\hline CT Cooling tower & 1,520 & $73.8 \%$ & 54.7 \\
\hline Natural gas, MWh/yr & & & $20,925.3$ \\
\hline Purchased electricity, MWh/yr & & & $1,060.7$ \\
\hline Dissipated cogenerated heat, $\mathrm{MWh} / \mathrm{yr}$ & & & 374.6 \\
\hline Natural gas, $\mathrm{k} € / \mathrm{yr}$ & & & 732.4 \\
\hline Purchased electricity, $\mathrm{k} € / \mathrm{yr}$ & & & 101.4 \\
\hline Annual fixed cost, $\mathrm{k} € / \mathrm{yr}$ & & & 181.7 \\
\hline Annual operation cost, $\mathrm{k} € / \mathrm{yr}$ & & & 833.8 \\
\hline Total annual cost, $\mathrm{k} € / \mathrm{yr}$ & & & $1,015.5$ \\
\hline Total investment cost, $\mathrm{k} €$ & & & $1,211.5$ \\
\hline Payback period, yr & & & 2.6 \\
\hline GE annual equivalent electric efficiency $E E E_{Y}$ & & & $66.7 \%$ \\
\hline GE annual heat efficiency $\eta_{q, Y}$ & & & $42.8 \%$ \\
\hline
\end{tabular}
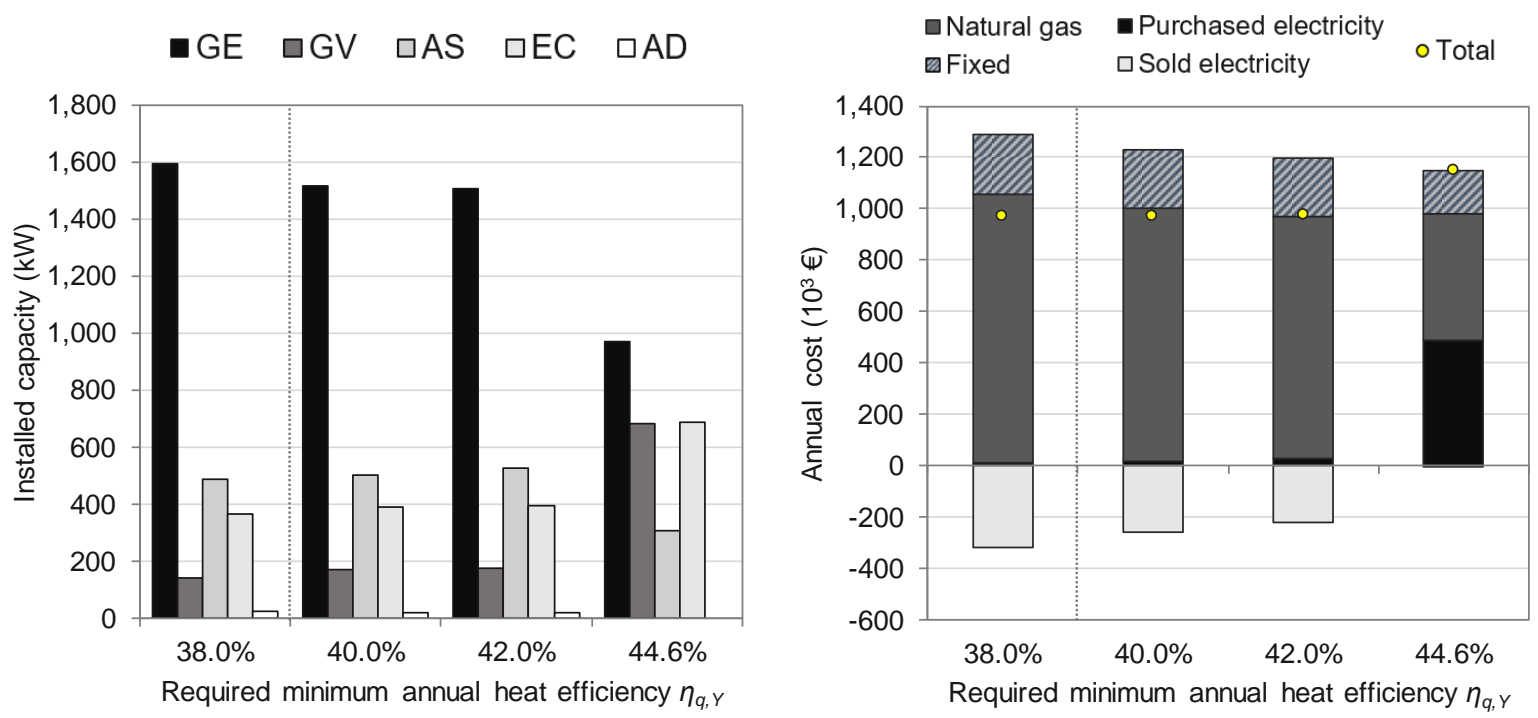

Figure 15: Variation of installed capacities and annual costs with the required minimum annual heat efficiency for the CCHP system. 


\subsection{Limitations and future perspectives}

This paper presented an ongoing investigation whose limitations and future perspectives are outlined herein. First of all, it is worth mentioning that the proposed model was intended as a pre-design approach. The obtained solutions did not correspond to final designs, on the contrary, they provided the basis for pre-feasibility analyses and the subsequent more in-depth design optimization process. Some of the simplifications made are inherent to the synthesis process, including the assumptions that the technologies could operate at any load, from zero to the installed capacity, without detriment to their performances, and there were no maximum activation times or a minimum operation duration. These limitations can be overcome by extending the synthesis model to the design optimization stage so that, once the technologies to be installed have been selected and the part of the model that describes the performances of the technologies has been refined, the design model determines the number of devices and their corresponding installed capacities. As a result, this would enable the model to incorporate a dispatch schedule that takes into account the effect of partial load operation and start, ramping and shutdown constraints on the system's performance.

In line with the previous limitation, it was assumed that the thermal energy flows associated with the technologies and the building were required/supplied at fixed temperatures and the heat exchange took place in a virtual heat exchangers network. In reality, however, technologies can be operated within their own suitable temperature ranges, affecting their performances. Besides, it may not be techno-economically viable to thermally integrate certain flows due to distance, space, cost, or safety considerations, which is likely to have overestimated the potential of heat recovery in the model. In this context, the proposed model could be enhanced by the optimal design of the heat exchangers network capable of operating with flexibility according to different operation modes, as cooling mode in the summer and heating mode in the winter. This poses a great challenge since the flexible operation will produce shifting Pinch points, as suggested in Section 3.3.

Since the goal of this paper was mainly to demonstrate the developed methodology, a relatively small superstructure was considered, although clearly it can be complemented by a greater variety of technologies including renewable energy technologies (e.g. solar photovoltaics, solar thermal collectors, biomass boilers, wind turbines), energy storage (e.g. thermal energy storage (TES), battery), cogeneration prime movers (e.g. gas turbine, microturbine, fuel cell), and ORC.

More particularly, it is well recognized that energy and economic benefits can be potentially obtained by incorporating TES units in cogeneration systems $[12,67]$. For the analyzed case study, it could be expected that the presence of TES units for hot water and/or chilled water would have reduced the mechanical chiller's installed capacity and increased those of the absorption chillers, as well as allowed for a more stable operation with higher load factors. Nevertheless, in accordance with Wang et al. [68], the temperature at which heat is stored as well as the temperature of the heat source are important factors for the integration of TES units into CCHP systems, especially for internal combustion engines given their various heat sources, which poses an additional challenge and constitutes an important future development of the synthesis methodology herein proposed. Regarding the role of batteries, it is unlikely that they would have been included in the optimal cost solutions, since the system was allowed to sell 
electricity to the electric grid at a very advantageous price, so the grid itself functioned as a kind of battery.

The model also assumed that input parameters were known beforehand and remained constant for the whole analysis duration. Actually, there are large uncertainties about the input data [30], including unforeseeable changes in economic (electricity and natural gas tariffs, investment costs, amortization and maintenance factor), regulatory (Brazilian net metering and qualified cogeneration regulations) and human (behavior and comfort habits affecting the energy demands) aspects, among others. Although sensitivity analyses have been performed for natural gas and electricity prices, penalization of the electricity selling price, amortization and maintenance factor, and minimum required GE annual heat efficiency, the uncertainties of energy demands, for instance, have not been addressed. This constitutes a worthwhile task for future research.

\section{Conclusions}

The benefits of polygeneration relative to the conventional separate production of energy services stem from the high degree of energy integration of its processes and thermal flows. This inherent characteristic represents one of the major challenges of the synthesis of such systems, which aims at determining what technologies to install and their corresponding capacities, typically with the minimum economic cost as the objective function. Given the combinatorial complexity of the problem (multiple energy resources, multiple energy products, multiple technology options, and multiple operation periods), the determination of a good system configuration requires first and foremost that the designer acknowledges that heat is not only available at different quantities and quality levels, but also that it is very likely to be distributed into different system components.

In this context, this paper looked at the use of thermal integration techniques in the synthesis optimization of energy supply systems for residential and commercial buildings. An innovative methodology was proposed for the synthesis of polygeneration systems for buildings with an appropriate thermal integration of technologies and utilities. The proposed OPT combines Pinch Analysis, by means of the problem table algorithm, and mathematical model, by means of MILP formulation, to achieve, through physical and structural constraints, a more realistic representation of technologies that supply and consume heat in the system. To stress the necessity of a detailed characterization of the technologies' thermal requirements and the importance of placing a value on the recoverable heat, a simple example was solved consisting of a gas engine-based energy system.

The methodology was then applied to the case study of a Brazilian university hospital. The technical and economic feasibility of installing various types of technologies, including gas engine, gas boilers, single- and double-effect absorption chillers, and mechanical chillers, was assessed. The MILP model was formulated and solved using the software LINGO. The results demonstrate that the CCHP system is the most appropriate solution to cover the hospital's energy demands not only on account of its high technical and economic feasibility, translated into low payback periods, but also because of its great resilience to variations in key parameters, 
as shown in the sensitivity analysis. Looking into the cooling production, the possibility of installing mechanical chillers, driven by purchased and/or self-generated electricity, provided an alternative production route that competed with absorption chillers. Besides, other concurrent thermal energy services, such as steam and hot water demands, vied with absorption chillers for the available heat. The optimal solution's installed cooling capacity corresponded to $60 \%$ of absorption chillers against $40 \%$ of mechanical chillers (this one only to cover peak demands). More particularly, most of the absorption cooling capacity corresponded to simpleeffect chillers, since the analyzed hospital had a significant demand for steam and a low demand for hot water. In this way, the gas engine's high-temperature heat was used to cover the steam demand and the remaining low-temperature heat was used to drive the simple-effect absorption chiller. Therefore, despite the lower COP, the single-effect absorption chiller was important to increase cogeneration's heat recovery levels, as indicated by the improved gas engine's heat efficiency in the CCHP configuration.

\section{Acknowledgements}

This work was developed in the frame of the research project ENE2017-87711-R, partially funded by the Spanish Government (Energy Program), the Government of Aragon (Ref: T5517R), Spain, and the EU Social Fund (FEDER Program 2014-2020 "Building Europe from Aragon"). Eduardo Pina acknowledges financial support from the Brazilian Federal Government and CNPq Science Without Borders Program.

\section{References}

[1] D.W. Wu, R.Z. Wang, Combined cooling, heating and power: A review, Prog. Energy Combust. Sci. 32 (2006) 459-495. https://doi.org/10.1016/j.pecs.2006.02.001.

[2] M. Liu, Y. Shi, F. Fang, Combined cooling, heating and power systems: A survey, Renew. Sustain. Energy Rev. 35 (2014) 1-22. https://doi.org/10.1016/j.rser.2014.03.054.

[3] H. Al Moussawi, F. Fardoun, H. Louahlia-Gualous, Review of tri-generation technologies: Design evaluation, optimization, decision-making, and selection approach, $\begin{array}{lllll}\text { Energy } & \text { Convers. } & \text { Manag. } & 120 & \text { (2016) }\end{array}$ https://doi.org/10.1016/j.enconman.2016.04.085.

[4] A. Rong, Y. Su, Polygeneration systems in buildings: A survey on optimization $\begin{array}{lllll}\text { approaches, } & \text { Energy } & \text { Build. } & 151 & \text { (2017) }\end{array}$ https://doi.org/10.1016/j.enbuild.2017.06.077.

[5] K. Jana, A. Ray, M.M. Majoumerd, M. Assadi, S. De, Polygeneration as a future sustainable energy solution - A comprehensive review, Appl. Energy. 202 (2017) 88111. https://doi.org/10.1016/j.apenergy.2017.05.129.

[6] G. Chicco, P. Mancarella, Distributed multi-generation: A comprehensive view, Renew. Sustain. Energy Rev. 13 (2009) 535-551. https://doi.org/10.1016/j.rser.2007.11.014. 
[7] L.M. Serra, M.A. Lozano, J. Ramos, A. V. Ensinas, S.A. Nebra, Polygeneration and efficient use of natural resources, Energy. 34 (2009) 575-586. https://doi.org/10.1016/j.energy.2008.08.013.

[8] IEA, Energy Technology Perspectives 2017 - Executive Summary, 2017. http://www.iea.org/publications/freepublications/publication/EnergyTechnologyPerspe ctives2017ExecutiveSummaryEnglishversion.pdf.

[9] E.A. Pina, M.A. Lozano, L.M. Serra, A multiperiod multiobjective framework for the synthesis of trigeneration systems in tertiary sector buildings, Int. J. Energy Res. (2019) 1-27. https://doi.org/10.1002/er.5006.

[10] P. Liu, M.C. Georgiadis, E.N. Pistikopoulos, An energy systems engineering approach for the design and operation of microgrids in residential applications, Chem. Eng. Res. Des. 91 (2013) 2054-2069. https://doi.org/10.1016/j.cherd.2013.08.016.

[11] R.R. Iyer, I.E. Grossmann, Synthesis and operational planning of utility systems for multiperiod operation, Comput. Chem. Eng. 22 (1998) 979-993. https://doi.org/10.1016/S0098-1354(97)00270-6.

[12] M.A. Lozano, J.C. Ramos, L.M. Serra, Cost optimization of the design of CHCP (combined heat, cooling and power) systems under legal constraints, Energy. 35 (2010) 794-805. https://doi.org/10.1016/j.energy.2009.08.022.

[13] T. Wakui, R. Yokoyama, Optimal structural design of residential cogeneration systems with battery based on improved solution method for mixed-integer linear programming, Energy. 84 (2015) 106-120. https://doi.org/10.1016/j.energy.2015.02.056.

[14] M.A. Lozano, J.C. Ramos, M. Carvalho, L.M. Serra, Structure optimization of energy supply systems in tertiary sector buildings, Energy Build. 41 (2009) 1063-1075. https://doi.org/10.1016/j.enbuild.2009.05.008.

[15] E.A. Pina, M.A. Lozano, L.M. Serra, Optimal design of polygeneration systems supported with renewable energy sources and energy storage for a Brazilian hospital, in: Proc. ECOS 2018, Guimaraes, Portugal, 2018.

[16] J. Deng, R.Z. Wang, G.Y. Han, A review of thermally activated cooling technologies for combined cooling, heating and power systems, Prog. Energy Combust. Sci. 37 (2011) 172-203. https://doi.org/10.1016/j.pecs.2010.05.003.

[17] M. Picón-Núñez, J.M. Medina-Flores, Process Integration Techniques for Cogeneration and Trigeneration Systems, Handb. Process Integr. Minimisation Energy Water Use, Waste Emiss. (2013) 484-504. https://doi.org/10.1533/9780857097255.4.484.

[18] J.C. Ramos, Optimización del diseño y operación de sistemas de cogeneración para el sector residencial comercial, PhD Thesis - University of Zaragoza, Department of Mechanical Engineering, 2012. https://zaguan.unizar.es/record/9901/files/TESIS-2012136.pdf.

[19] M.R. Linnhoff B, Townsend D, Boland D, Hewitt G, Thomas B, Guy A, User guide on process integration for the efficient use of energy, Institution of Chemical Engineers. Rugby, UK: IchemE, 1982. 
[20] I.C. Kemp, Pinch analysis and process integration. A user guide on process integration for the efficient use of energy, 2nd ed., Butterworth-Heinemann/Elsevier, 2007.

[21] J.J. Klemeš, Handbook of Process Integration, Elsevier, 2013.

[22] M.M. El-Halwagi, Sustainable Design Through Process Integration, Elsevier, 2017.

[23] S.A. Papoulias, I.E. Grossmann, A structural optimization approach in process synthesis-II, Comput. Chem. Eng. 7 (1983) 707-721. https://doi.org/10.1016/00981354(83)85023-6.

[24] F. Maréchal, Mèthode d'analyse et de synthèse énergétiques des procédés industriels, PhD Thesis - Faculté des Sciences Appliquées, Collection des publications n. 124, Université de Liège, 1995.

[25] Z. Shang, A. Kokossis, A systematic approach to the synthesis and design of flexible site utility systems, Chem. Eng. Sci. $60 \quad$ (2005) 4431-4451. https://doi.org/10.1016/j.ces.2005.03.015.

[26] M. Ameri, Z. Besharati, Optimal design and operation of district heating and cooling networks with CCHP systems in a residential complex, Energy Build. 110 (2016) 135148. https://doi.org/10.1016/j.enbuild.2015.10.050.

[27] A. Ondeck, T.F. Edgar, M. Baldea, A multi-scale framework for simultaneous optimization of the design and operating strategy of residential CHP systems, Appl. Energy. 205 (2017) 1495-1511. https://doi.org/10.1016/j.apenergy.2017.08.082.

[28] S.G. Sigarchian, A. Malmquist, V. Martin, Design optimization of a complex polygeneration system for a hospital, Energies. $11 \quad$ (2018). https://doi.org/10.3390/en11051071.

[29] L.F. Fuentes-Cortés, J.M. Ponce-Ortega, F. Nápoles-Rivera, M. Serna-González, M.M. El-Halwagi, Optimal design of integrated CHP systems for housing complexes, Energy Convers. Manag. 99 (2015) 252-263. https://doi.org/10.1016/j.enconman.2015.04.036.

[30] L. Urbanucci, D. Testi, Optimal integrated sizing and operation of a CHP system with Monte Carlo risk analysis for long-term uncertainty in energy demands, Energy Convers. Manag. 157 (2018) 307-316. https://doi.org/10.1016/j.enconman.2017.12.008.

[31] L. Li, H. Mu, N. Li, M. Li, Economic and environmental optimization for distributed energy resource systems coupled with district energy networks, Energy. 109 (2016) 947960. https://doi.org/10.1016/j.energy.2016.05.026.

[32] C.Y. Zheng, J.Y. Wu, X.Q. Zhai, R.Z. Wang, Impacts of feed-in tariff policies on design and performance of CCHP system in different climate zones, Appl. Energy. 175 (2016) 168-179. https://doi.org/10.1016/j.apenergy.2016.05.005.

[33] Y. Wang, N. Zhang, Z. Zhuo, C. Kang, D. Kirschen, Mixed-integer linear programmingbased optimal configuration planning for energy hub: Starting from scratch, Appl. Energy. 210 (2018) 1141-1150. https://doi.org/10.1016/j.apenergy.2017.08.114.

[34] Q. Zhu, X. Luo, B. Zhang, Y. Chen, Mathematical modelling and optimization of a large- 
scale combined cooling, heat, and power system that incorporates unit changeover and time-of-use electricity price, Energy Convers. Manag. 133 (2017) 385-398. https://doi.org/10.1016/j.enconman.2016.10.056.

[35] C.L. Sy, K.B. Aviso, A.T. Ubando, R.R. Tan, Target-oriented robust optimization of polygeneration systems under uncertainty, Energy. 116 (2016) 1334-1347. https://doi.org/10.1016/j.energy.2016.06.057.

[36] H. Bahlawan, M. Morini, M. Pinelli, W.R. Poganietz, P.R. Spina, M. Venturini, Optimization of a hybrid energy plant by integrating the cumulative energy demand, Appl. Energy. 253 (2019) 113484. https://doi.org/10.1016/j.apenergy.2019.113484.

[37] D. Wu, Z. Han, Z. Liu, H. Zhang, Study on configuration optimization and economic feasibility analysis for combined cooling, heating and power system, Energy Convers. Manag. 190 (2019) 91-104. https://doi.org/10.1016/j.enconman.2019.04.004.

[38] M. Carvalho, M.A. Lozano, L.M. Serra, Multicriteria synthesis of trigeneration systems considering economic and environmental aspects, Appl. Energy. 91 (2012) 245-254. https://doi.org/10.1016/j.apenergy.2011.09.029.

[39] K. Gluesenkamp, Y. Hwang, R. Radermacher, High efficiency micro trigeneration systems, Appl. Therm. Eng. 50 (2013) 1480-1486. https://doi.org/10.1016/j.applthermaleng.2011.11.062.

[40] G. Oluleye, R. Smith, A mixed integer linear programming model for integrating thermodynamic cycles for waste heat exploitation in process sites, Appl. Energy. 178 (2016) 434-453. https://doi.org/10.1016/j.apenergy.2016.06.096.

[41] A.S. Wallerand, M. Kermani, I. Kantor, F. Maréchal, Optimal heat pump integration in industrial processes, Appl. Energy. $219 \quad$ (2018) 68-92. https://doi.org/10.1016/j.apenergy.2018.02.114.

[42] M. Mirzaee, R. Zare, M. Sadeghzadeh, H. Maddah, M.H. Ahmadi, E. Ac1kkalp, L. Chen, Thermodynamic analyses of different scenarios in a CCHP system with micro turbine Absorption chiller, and heat exchanger, Energy Convers. Manag. 198 (2019). https://doi.org/10.1016/j.enconman.2019.111919.

[43] Y. Jung, J. Kim, H. Lee, Multi-criteria evaluation of medium-sized residential building with micro-CHP system in South Korea, Energy Build. 193 (2019) 201-215. https://doi.org/10.1016/j.enbuild.2019.03.051.

[44] K.F. Fong, C.K. Lee, Performance analysis of internal-combustion-engine primed trigeneration systems for use in high-rise office buildings in Hong Kong, Appl. Energy. 160 (2015) 793-801. https://doi.org/10.1016/j.apenergy.2014.11.059.

[45] B.J. Hipólito-Valencia, E. Rubio-Castro, J.M. Ponce-Ortega, M. Serna-González, F. Nápoles-Rivera, M.M. El-Halwagi, Optimal design of inter-plant waste energy integration, Appl. Therm. Eng. 62 (2014) 633-652. https://doi.org/10.1016/j.applthermaleng.2013.10.015.

[46] T. Wissocq, S. Ghazouani, S. Le Bourdiec, A methodology for designing thermodynamic energy conversion systems in industrial mass/heat integration problems based on MILP 
models, Energy. 185 (2019) 121-135. https://doi.org/10.1016/j.energy.2019.06.124.

[47] P.Y. Liew, W.L. Theo, S.R. Wan Alwi, J.S. Lim, Z. Abdul Manan, J.J. Klemeš, P.S. Varbanov, Total Site Heat Integration planning and design for industrial, urban and renewable systems, Renew. Sustain. Energy Rev. 68 (2017) 964-985. https://doi.org/10.1016/j.rser.2016.05.086.

[48] P.Y. Liew, T.G. Walmsley, S.R. Wan Alwi, Z. Abdul Manan, J.J. Klemeš, P.S. Varbanov, Integrating district cooling systems in Locally Integrated Energy Sectors through Total Site Heat Integration, Appl. Energy. 184 (2016) 1350-1363. https://doi.org/10.1016/j.apenergy.2016.05.078.

[49] E.T. Calva, M.P. Núñez, M.A.R. Toral, Thermal integration of trigeneration systems, Appl. Therm. $\quad$ Eng. $25 \quad$ (2005) 973-984. https://doi.org/10.1016/j.applthermaleng.2004.06.022.

[50] M. Bohlayer, G. Zöttl, Low-grade waste heat integration in distributed energy generation systems - An economic optimization approach, Energy. 159 (2018) 327-343. https://doi.org/10.1016/j.energy.2018.06.095.

[51] X. Wang, M. Jin, W. Feng, G. Shu, H. Tian, Y. Liang, Cascade energy optimization for waste heat recovery in distributed energy systems, Appl. Energy. 230 (2018) 679-695. https://doi.org/10.1016/j.apenergy.2018.08.124.

[52] C. Lythcke-Jørgensen, A.V. Ensinas, M. Münster, F. Haglind, A methodology for designing flexible multi-generation systems, Energy. $110 \quad$ (2016) 34-54. https://doi.org/10.1016/j.energy.2016.01.084.

[53] WÄRTSILÄ, Wärtsilä 34DF Product Guide, (2016).

[54] E.A. Pina, Thermoeconomic and environmental synthesis and optimization of polygeneration systems supported with renewable energies and thermal energy storage applied to the residential-commercial sector, PhD Thesis - University of Zaragoza, Department of Mechanical Engineering, 2019. https://zaguan.unizar.es/record/87519.

[55] D.B. Espirito Santo, An energy and exergy analysis of a high-efficiency engine trigeneration system for a hospital: A case study methodology based on annual energy demand profiles, Energy Build. 76 (2014) 185-198. https://doi.org/10.1016/j.enbuild.2014.02.014.

[56] COMGAS, Natural gas rates, (2018). https://www.comgas.com.br/tarifas/.

[57] CPFL, Electricity rates, CPFL Paul. https://www.cpflempresas.com.br/institucional/tarifas.aspx?emp=CPFL.

[58] ANEEL, Normative Resolution 235/2006 on qualified cogeneration, (2006).

[59] L. Schrage, Optimization modeling with LINGO, Lindo Systems, 1999.

[60] Q. Wu, H. Ren, W. Gao, J. Ren, Multi-criteria assessment of combined cooling, heating and power systems located in different regions in Japan, Appl. Therm. Eng. 73 (2014) 660-670. https://doi.org/10.1016/j.applthermaleng.2014.08.020. 
[61] G. Yang, X.Q. Zhai, Optimal design and performance analysis of solar hybrid CCHP system considering influence of building type and climate condition, Energy. 174 (2019) 647-663. https://doi.org/10.1016/j.energy.2019.03.001.

[62] A. Costa, A. Fichera, A mixed-integer linear programming (MILP) model for the evaluation of CHP system in the context of hospital structures, Appl. Therm. Eng. 71 (2014) 921-929. https://doi.org/10.1016/j.applthermaleng.2014.02.051.

[63] B.C.T. de Carvalho, C.T.M.C.B. de Melo, A.J.R. Freire, S. Khanmohammadi, M. Carvalho, Multicriteria optimization of renewable-based polygeneration system for tertiary sector buildings, Environ. Eng. Manag. J. 18 (2019) 2441-2453. https://doi.org/10.30638/eemj.2019.232.

[64] H. Ahn, J.D. Freihaut, D. Rim, Economic feasibility of combined cooling, heating, and power (CCHP) systems considering electricity standby tariffs, Energy. 169 (2019) 420432. https://doi.org/10.1016/j.energy.2018.11.126.

[65] H. Ahn, D. Rim, J.D. Freihaut, Performance assessment of hybrid chiller systems for combined cooling, heating and power production, Appl. Energy. 225 (2018) 501-512. https://doi.org/10.1016/j.apenergy.2018.05.045.

[66] A. Piacentino, R. Gallea, F. Cardona, V. Lo Brano, G. Ciulla, P. Catrini, Optimization of trigeneration systems by Mathematical Programming: Influence of plant scheme and boundary conditions, Energy Convers. Manag. 104 (2015) 100-114. https://doi.org/10.1016/j.enconman.2015.03.082.

[67] Y. Ruan, Q. Liu, Z. Li, J. Wu, Optimization and analysis of Building Combined Cooling, Heating and Power (BCHP) plants with chilled ice thermal storage system, Appl. Energy. 179 (2016) 738-754. https://doi.org/10.1016/j.apenergy.2016.07.009.

[68] J. Wang, X. Xie, Y. Lu, B. Liu, X. Li, Thermodynamic performance analysis and comparison of a combined cooling heating and power system integrated with two types of thermal energy storage, Appl. Energy. 219 (2018) 114-122. https://doi.org/10.1016/j.apenergy.2018.03.029. 


\section{Nomenclature}

Abbreviations and acronyms

AD Double-Effect Absorption Chiller

ANEEL Brazilian Electricity Regulatory Agency

AS Single-Effect Absorption Chiller

CCHP Combined Cooling, Heating and Power

CHP Combined Heat and Power

COP Coefficient of Performance

CT Cooling Tower

DHC District Heating and Cooling

DHW Domestic Hot Water

EC Mechanical Chiller

GE Cogeneration Module

GH Natural Gas Hot Water Boiler

GT Gas turbine

GV Natural Gas Steam Boiler

HEN Heat exchangers network

ICE Internal combustion engine

LHV Lower Heating Value

MILP Mixed Integer Linear Programming

MOO Multi-objective optimization

OPT Open Problem Table

ORC Organic Rankine Cycle

TAT Thermally Activated Technology

TES Thermal Energy Storage

US United States of America

VAP Saturated steam

Indices

$d \quad$ Representative day

$h \quad$ Hourly period

$i \quad$ Hot flow

j Cold flow 
$k \quad$ Temperature interval

$t \quad$ Technology

Symbols

$B D \quad$ Exergy content of the flow, $\mathrm{kW}$

CI Bare module cost, $€ / \mathrm{kW}$

$\operatorname{cpd}(j, k)$ Specific heat of the cold flow $j$ present in $k, \mathrm{~kJ} /(\mathrm{kg} \cdot \mathrm{K})$

cpo $(i, k)$ Specific heat of the hot flow $i$ present in $k, \mathrm{~kJ} /(\mathrm{kg} \cdot \mathrm{K})$

$C T E_{f i x} \quad$ Annual fixed cost, $€ / \mathrm{yr}$

$C T E_{\text {tot }}$ Total annual cost, $€ / \mathrm{yr}$

$C T E_{\text {var }} \quad$ Annual operation cost, $€ / \mathrm{yr}$

CUe Unit auxiliary electricity consumption, $\mathrm{kWel} / \mathrm{kW}$

$D K(k, \theta)$ Heat consumed by the cold flows present in $k$ in the time interval $\theta, \mathrm{kW}$

$E_{d} \quad$ Electricity demand, $\mathrm{kW}$

$E E E_{Y} \quad$ Annual equivalent electric efficiency, \%

$E_{p} \quad$ Electricity purchased from the grid, $\mathrm{kW}$

$E_{s} \quad$ Electricity sold to the grid, $\mathrm{kW}$

fam Amortization and maintenance factor, $\mathrm{yr}^{-1}$

$F_{g e} \quad$ Natural gas consumption by the engine, $\mathrm{kW}$

$F_{g e}{ }^{\mathrm{b}} \quad$ Exergy content of the natural gas, $\mathrm{kW}$

$F_{g h} \quad$ Natural gas consumption by the $\mathrm{GH}, \mathrm{kW}$

$F_{g v} \quad$ Natural gas consumption by the $\mathrm{GV}, \mathrm{kW}$

$f_{I C} \quad$ Indirect costs factor, -

$F_{p} \quad$ Natural gas consumed by the system, $\mathrm{kW}$

$\operatorname{lhd}(j, k)$ Latent heat of the cold flow $j$ present in $k, \mathrm{~kJ} / \mathrm{kg}$

Iho(i,k) Latent heat of the hot flow $i$ present in $k, \mathrm{~kJ} / \mathrm{kg}$

$m d(j, \theta)$ Mass flow rate of the cold flow $j$ in the time interval $\theta, \mathrm{kg} / \mathrm{s}$

$m d u(j) \quad$ Unit mass flow rate of the cold flow $j$ per $\mathrm{kW}$ of installed capacity, $(\mathrm{kg} / \mathrm{s}) / \mathrm{kW}$

$m o(i, \theta)$ Mass flow rate of the hot flow $i$ in the time interval $\theta, \mathrm{kg} / \mathrm{s}$

$\operatorname{mou}(i)$ Unit mass flow rate of the hot flow $i$ per $\mathrm{kW}$ of installed capacity, $(\mathrm{kg} / \mathrm{s}) / \mathrm{kW}$

MP $\quad$ Maximum production, $\mathrm{kW}$

$N H P(h)$ Number of hours per period

NP Number of periods 
NRD Number of representative days per year

$N R Y(d)$ Number of representative days type $d$ per year

nyr Operational lifetime of the plant, yr

$O K(k, \theta)$ Heat supplied by the hot flows present in $\mathrm{k}$ in the time interval $\theta, \mathrm{kW}$

$\operatorname{OPECAP}(\theta) \quad$ Partial operating load of the device's main product in the time interval $\theta, \mathrm{kW}$

$p_{e p} \quad$ Electricity purchase price, $€ / \mathrm{kWh}$

$p_{e s} \quad$ Electricity selling price, $€ / \mathrm{kWh}$

$p_{\text {gas }} \quad$ Natural purchase price, $€ / \mathrm{kWh}(\mathrm{LHV})$

$P I N(t) \quad$ Installed capacity of technology $t, \mathrm{~kW}$

$\operatorname{PIN}_{\text {MAX }}(t) \quad$ Maximum installable capacity of technology $t, \mathrm{~kW}$

$Q_{a c} \quad$ Charge air heat, $\mathrm{kW}$

$Q_{a d} \quad$ Heat consumed by the $\mathrm{AD}, \mathrm{kW}$

Qas Heat consumed by the AS, kW

Qd Hot water demand, $\mathrm{kW}$

$Q D(j, \theta)$ Heat consumed by the cold flow $j$ in the time interval $\theta, \mathrm{kW}$

$Q_{\text {dis }} \quad$ Dissipated heat, $\mathrm{kW}$

$Q_{\text {dis,ad }} \quad$ Dissipated heat from the $\mathrm{AD}, \mathrm{kW}$

$Q_{\text {dis,as }} \quad$ Dissipated heat from the AS, kW

$Q_{d i s, c t} \quad$ Dissipated heat from the CT, kW

$Q_{\text {dis,ec }} \quad$ Dissipated heat from the EC, $\mathrm{kW}$

$Q_{\text {dis,int }}$ Dissipated heat from the thermal integration subsystem, $\mathrm{kW}$

$Q_{e g} \quad$ Exhaust gas heat, $\mathrm{kW}$

$Q_{g e} \quad$ Total cogenerated heat, $\mathrm{kW}$

$Q_{g h} \quad$ Heat supplied by the $\mathrm{GH}, \mathrm{kW}$

$Q_{g v} \quad$ Heat supplied by the GV, kW

$Q I K(i, k, \theta) \quad$ Heat supplied by the hot flow $i$ present in $k$ in the time interval $\theta, \mathrm{kW}$

$Q J K(j, k, \theta) \quad$ Heat consumed by the cold flow $j$ present in $k$ in the time interval $\theta, \mathrm{kW}$

$Q_{j w} \quad$ Jacket cooling water heat, $\mathrm{kW}$

$Q_{l o} \quad$ Lubricating oil heat, $\mathrm{kW}$

$Q O(i, \theta)$ Heat supplied by the hot flow $i$ in the time interval $\theta, \mathrm{kW}$

$R_{a d} \quad$ Chilled water produced by the $\mathrm{AD}, \mathrm{kW}$

$R_{a s} \quad$ Chilled water produced by the AS, kW

$R_{d} \quad$ Cooling demand, $\mathrm{kW}$ 
$R_{e c} \quad$ Chilled water produced by the EC, $\mathrm{kW}$

$R K(k, \theta)$ Surplus heat of $k$ in the time interval $\theta, \mathrm{kW}$

$T_{0} \quad$ Reference ambient temperature, $\mathrm{K}$

$T_{\text {in }} \quad$ Supply temperature, ${ }^{\circ} \mathrm{C}$

$T_{\text {in }}{ }^{*} \quad$ Shifted supply temperature, ${ }^{\circ} \mathrm{C}$

$T_{m} \quad$ Phase change temperature, $\mathrm{K}$

$T_{\text {out }} \quad$ Target temperature, ${ }^{\circ} \mathrm{C}$

$T_{\text {out }}{ }^{*} \quad$ Shifted target temperature, ${ }^{\circ} \mathrm{C}$

$V_{d} \quad$ Steam demand, $\mathrm{kW}$

$W_{\text {aux }} \quad$ Auxiliary electricity, $\mathrm{kW}$

$W_{e c} \quad$ Electricity consumed by the EC, $\mathrm{kW}$

$W_{g e} \quad$ Net electrical power of the engine, $\mathrm{kW}$

$y E p \quad$ Binary variable expressing the permission to purchase or not (1/0) electricity from the grid

$y E s \quad$ Binary variable expressing the permission to sell or not (1/0) electricity to the grid

$y I N S(t)$ Binary variable expressing the permission or not (1/0) to install the technology $t$

Greek symbols

$\Delta h d(j, k)$ Enthalpy change of the cold flow $j$ present in $k, \mathrm{~kJ} / \mathrm{kg}$

$\Delta h o(i, k)$ Enthalpy change of the hot flow $i$ present in $k, \mathrm{~kJ} / \mathrm{kg}$

$\Delta T(k) \quad$ Temperature difference of the temperature interval $k, \mathrm{~K}$

$\varepsilon \quad$ Exergy efficiency, \%

$\eta \quad$ Energy efficiency, $\%$

$\eta_{c} \quad$ Cooling efficiency, $\%$

$\eta_{q} \quad$ Heat efficiency, $\%$

$\eta_{w} \quad$ Electric efficiency, $\%$

$\theta \quad$ Time interval 